\title{
ANÁLISE DE IMAGENS DIGITAIS NA AVALIAÇÃO DE PLÂNTULAS DE MILHO
}

\author{
Everton Felix TEIXEIRA
}

Tese apresentada à Escola Superior de Agricultura

"Luiz de Queiroz", Universidade de São Paulo, para obtenção do título de Doutor em Agronomia, Área de Concentração: Fitotecnia.

\author{
PIRACICABA \\ Estado de São Paulo - Brasil \\ Novembro - 2004
}




\title{
ANÁLISE DE IMAGENS DIGITAIS NA AVALIAÇÃO DE PLÂNTULAS DE MILHO
}

\author{
EVERTON FELIX TEIXEIRA \\ Engenheiro Agrônomo
}

Orientador: Prof. Dr. SILVIO MOURE CICERO Co-Orientador: Prof. Dr. DURVAL DOURADO NETO

Tese apresentada à Escola Superior de Agricultura

"Luiz de Queiroz", Universidade de São Paulo, para obtenção do título de Doutor em Agronomia, Área de Concentração: Fitotecnia.

\author{
PIRACICABA \\ Estado de São Paulo - Brasil \\ Novembro - 2004
}


Dados Internacionais de Catalogação na Publicação (CIP)
DIVISÃO DE BIBLIOTECA E DOCUMENTAÇÃO - ESALQ/USP

Teixeira, Everton Felix

Análise de imagens digitais na avaliação de plântulas de milho / Everton Felix

Teixeira. - - Piracicaba, 2004

57 p. : il.

Tese (Doutorado) - - Escola Superior de Agricultura Luiz de Queiroz, 2004.

Bibliografia.

1. Imagem digital 2. Milho 3. Plântula 4. Processamento de imagens 5.

Semente 6. Sistema radicular 7. Teste de vigor I. Título

CDD 633.15

"Permitida a cópia total ou parcial deste documento, desde que citada a fonte - O autor" 
Aos meus amados pais, Railda Felix Teixeira e Luiz Garcia Teixeira; e aos meus amados irmãos Andrei e Miller:

OFEREÇO.

À minha amada, Maria Luisa:

DEDICO. 


\section{CICLO}

Parecia que novamente se irrompia

Em tedioso estar naquela mata,

Ainda...!

Sob o céu derrubando água,

Soprando, gritando, matando,

Permanecendo em luto...

Lavava aos poucos o sentimento de domínio

De quem estava forçadamente a observar,

Ascendia a noção da espreita,

Puramente animal,

Redundante perante o inesperado...

A alegria do estar vivo brotava

Do susto e não da certeza

Assim como mergulhado no tédio,

Aprendia-se a esperar.

O tempo consumia o medo

Enquanto se reconstruía noutro tempo

Sendo a própria explicação da natural rebeldia!

A natureza, afoita pela mudança,

Rebelava-se em dessimetria...

Tornando áspera a pele macia

Expondo o que antes não se via

Reconstruindo formas e imagens

Em instantes...

Luzes!

Reluziam relâmpagos!

Trovejos calavam o apelo das chamas nos arvoredos tortos

Arpejando ao estalar dos galhos banidos

Já caídos na água que corria...

Um ciclo de acontecimentos

Impunha as necessidades ao extremo!

Porém, botões afirmavam que o ato mereceria flores!

$E$ dos ovos que restavam nos ninhos

Sairiam novos cantos de liberdade...

Em todos os momentos

Destas longas eras, foi assim!

Nem bem cedo, nem tão tarde...

Nunca ou sempre... Quase!

E, enfim...

O Sol!

Suspenso...

Sustenta por entre as noites

A verdadeira esperança. 


\section{AGRADECIMENTOS}

À Universidade de São Paulo - Escola Superior de Agricultura "Luiz de Queiroz" - Departamento de Produção Vegetal, pela honra de poder realizar o Curso de Doutorado e pela oportunidade de evoluir academicamente.

Ao professor Doutor Silvio Moure Cicero, pela amizade, apoio, incentivo e ensinamentos passados ao longo da minha formação, pela sua pessoa e seu profissionalismo como pesquisador, orientador e educador. Muito obrigado.

Ao professor Doutor Durval Dourado Neto, pela amizade, ensinamentos valiosos e incalculáveis, palavras que me aconselharam fortalecendo minha admiração, pelo incentivo, pelo profissionalismo através de anos de luta. Muito obrigado.

Ao professor Doutor Walter Rodrigues da Silva, ao professor Doutor Julio Marcos Filho e à Doutora Ana Dionísia da Luz Coelho Novembre, pela amizade, sugestões e especial atenção ao meu trabalho.

À Eng $^{\circ}$ Agr $^{\circ}$ MSc. Helena M. C. Pescarin Chamma, pela amizade e suporte no Laboratório de Análise de Sementes enquanto prosseguia com minha pesquisa.

À CAPES, pelo fomento à minha pesquisa. 
Aos funcionários do Departamento de Produção Vegetal e Laboratório de Análise de Sementes da Escola Superior de Agricultura "Luiz de Queiroz" USP, em especial à Ilze Helena Neves, à Luciane Aparecida Lopes, ao João Jabour e ao Odair Luiz Banzatto Júnior, pela amizade e pela colaboração.

Especialmente aos meus amigos irmãos, Eng $^{\circ}$ Agr $^{\circ}$ MSc. Rodrigo Ayusso Guerzoni e Eng $^{\circ}$ Agr $^{\circ}$ Marcos Colossio, por me apoiarem no cultivo dessa idéia.

Absolutamente a todos que pelos meandros desta vida puderam ampliar a minha consciência, fazendo-me prosseguir na evolução como ser humano. 


\section{SUMÁRIO}

Página

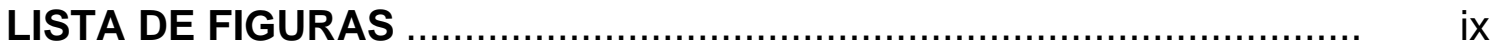

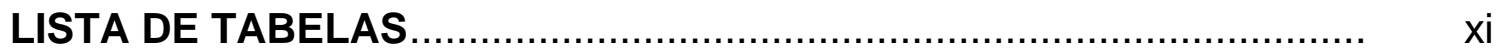

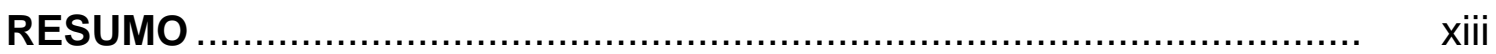

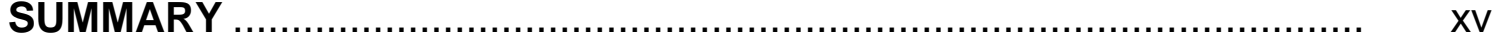

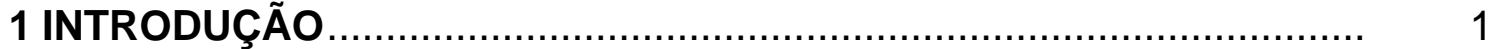

2 REVISÃO DE LITERATURA …....................................................... 2

2.1 Qualidade fisiológica de sementes............................................... 2

2.2 Captação, processamento, reconhecimento e análise de imagens...... 5

2.2.1 Imagem padrão e imagem digital .................................................. 5

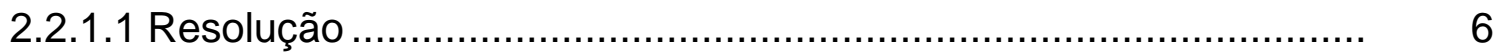

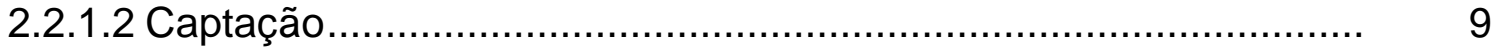

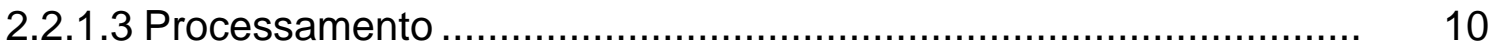

2.2.1.4 Conversão e segmentação ..................................................... 13

2.2.1.5 Filtros e representações......................................................... 14

2.2.1.6 Reconhecimento e análise de imagens ..................................... 15

3 MATERIAL E MÉTODOS ........................................................ 17

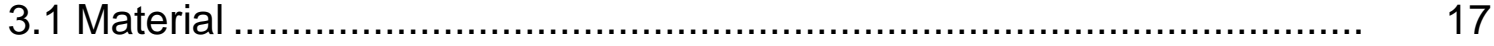

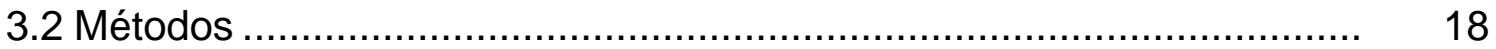

3.2.1 Teste de crescimento de plântulas.............................................. 18

3.2.2 Digitalização da imagem ......................................................... 19

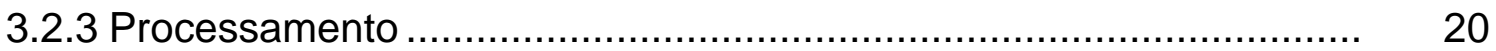

3.2.4 Teor de água da semente ................................................... 21 
3.2.5 Teste de germinação ................................................... 21

3.2.6 Teste de envelhecimento acelerado .................................... 21

3.2.7 Teste de condutividade elétrica......................................... 22

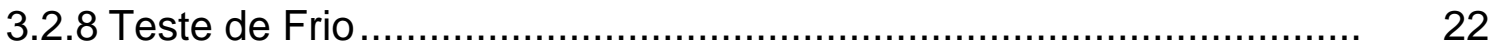

3.2.9 Análise estatística dos resultados ...................................... 22

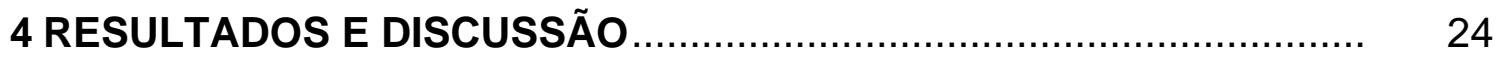

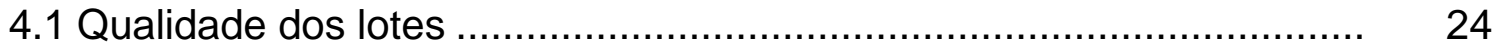

4.2 Potencial fisiológico através do teste de crescimento de plântulas....... 26

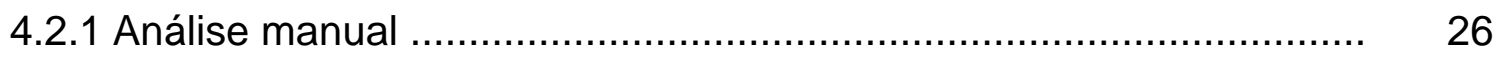

4.2.2 Análise pelo processamento de imagens digitais ........................ 27

4.2.2.1 Coleóptilo e raiz principal ............................................ 39

4.2.2.2 Coleóptilo e sistema radicular ......................................... 41

4.3 Considerações finais ............................................................. 44

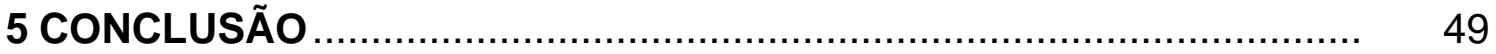

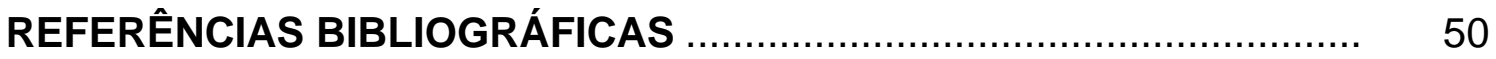




\section{LISTA DE FIGURAS}

Página

1 Esquerda: semente de milho captada em imagem de 100 dpi, 256 tons de cinza e 8 bits. Direita: ampliada $7 x$ em tela $(700 \%)$................... 7

2 Passos fundamentais no processamento de uma imagem digital .......... 12

3 Dados do procedimento manual de medição usual do comprimento do coleóptilo mais a raiz principal (CRPm) de plântulas dos cinco lotes, em amostras de duzentas sementes inicialmente semeadas................. 27

4 Imagem digital amostrada do lote 1, pronta para a análise com o uso da rotina de processamento .......................................................... 30

5 Imagem digital amostrada do lote 2, pronta para a análise com o uso da rotina de processamento ......................................................... 31

6 Imagem digital amostrada do lote 3, pronta para a análise com o uso da rotina de processamento ........................................................... 32

7 Imagem digital amostrada do lote 4, pronta para a análise com o uso

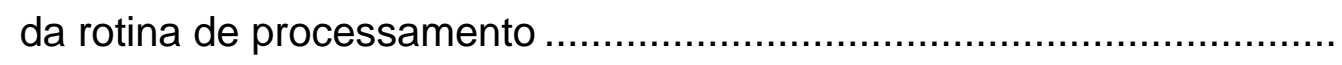

8 Imagem digital amostrada do lote 5, pronta para a análise com o uso

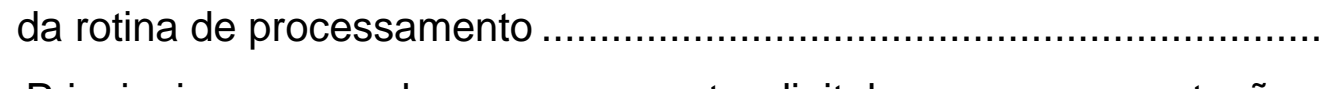

9 Principais passos do processamento digital como representações estáticas, seguindo: 256 tons em escala de cinza (A), imagem binária (B), esqueleto em imagem binária com pequenos objetos removidos (C), medição com o algoritmo "contador de pixels" (D) ......................... 
10 Seqüência esquemática de processamento: imagem binária $(A)$, esqueleto em imagem binária (B), detecção e medição pelo algoritmo "contador de pixels", via análise de unidades discretas (C)

11 Pré-processamento em imagem digital (esquerda) para alteração, com a retirada das menores raízes da plântula (direita)

12 Dados do procedimento computacional de medição usual do comprimento do coleóptilo mais a raiz principal (CRPp) de plântulas dos cinco lotes, em amostras de duzentas sementes inicialmente semeadas

13 Dados do procedimento computacional de medição não usual do comprimento do coleóptilo mais o sistema radicular (CSRp) de plântulas dos cinco lotes, em amostras de duzentas sementes inicialmente semeadas

14 Comprimento médio das plântulas dos cinco lotes, sendo as avaliações do coleóptilo mais sistema radicular via processamento (CSRp), do coleóptilo mais raiz principal via processamento (CRPp) e do coleóptilo mais raiz principal via medição manual (CRPm)

15 Formação de sombras numa imagem digital podendo causar falhas de integridade no objeto em processamento 


\section{LISTA DE TABELAS}

Página

1 Qualidade das sementes dos cinco lotes analisados, avaliada inicialmente, onde se observa: teor de água (TA), teste de germinação (TG), condutividade elétrica (CE), envelhecimento

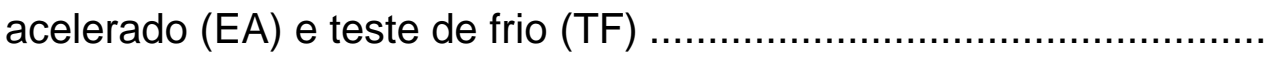

2 Rotina computacional nomeada EFT_SkiLLMeasure versão 3.3 referente à mensuração do comprimento de plântulas intactas de milho, analisadas através do processamento da imagem, na

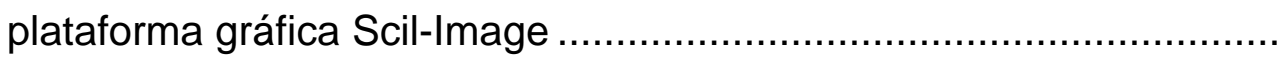

3 Qualidade das sementes dos cinco lotes analisados, avaliada pelo teste de crescimento de plântulas, onde se observa: CRPm (coleóptilo mais raiz principal via medição manual), CRPp (coleóptilo mais raiz principal via processamento), CSRp (coleóptilo

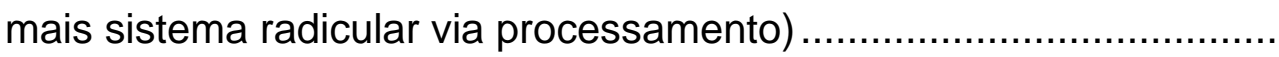

4 Classificação estatística do conjunto A formado pela pontuação dos testes usuais pontuação geral, formação de grupos SPM (Superior ao Médio), IM (Inferior ao Médio) e M (Médio = pontuação nula), divisão em classes de potenciais fisiológicos (PFMaior, PFMenor e PFIntermediário, onde se observa: condutividade elétrica (CE), envelhecimento acelerado (EA) e teste de frio (TF) 
5 Classificação estatística do conjunto $B$ e contagem do número de lotes pertencentes ao mesmo grupo para os conjuntos de testes $A$ e B com o cálculo da taxa de coincidência ( $\left.T C^{*}\right)$, onde se observa: CRPm (coleóptilo mais raiz principal via medição manual), CRPp (coleóptilo mais raiz principal via processamento), CSRp (coleóptilo mais sistema radicular via processamento) ....................................... 


\title{
ANÁLISE DE IMAGENS DIGITAIS NA AVALIAÇÃO DE PLÂNTULAS DE MILHO
}

\author{
Autor: EVERTON FELIX TEIXEIRA \\ Orientador: Prof. Dr. SILVIO MOURE CICERO \\ Co-Orientador: Prof. Dr. DURVAL DOURADO NETO
}

\section{RESUMO}

A análise de imagens digitais tem grande potencial de uso na determinação do vigor de sementes. Associada ao teste de crescimento de plântulas, essa técnica possibilita a análise dimensional de imagens com rapidez e precisão. O resultado é a extensão total de cada plântula via quantificação computadorizada do comprimento de suas partes constituintes. Assim, o objetivo do trabalho foi estudar o vigor de lotes de sementes de milho, por meio do teste de crescimento de plântulas, utilizando-se a análise de imagens. Plântulas de milho (genótipo AG122) foram retiradas do germinador ao quarto dia de desenvolvimento e ordenadas sobre uma folha de poliéster transparente na superfície de um "scanner" para a captação das imagens. Desenvolveu-se uma rotina de processamento no programa "Scil-Image" para a análise das imagens digitais obtidas das plântulas. Houve medição computadorizada da extensão total, com a soma usual do comprimento do coleóptilo ao comprimento da maior raiz da plântula e, também, não usualmente, ao tamanho de todo sistema radicular. As plântulas foram 
mensuradas manualmente, visando a comparação com o método em estudo. Os resultados mostraram que a técnica digital possibilita a associação dos dados obtidos no processamento a eventuais diferenças de vigor existentes em lotes de sementes de milho, de maneira similar a outros métodos destinados à avaliação do vigor de sementes da referida espécie. 


\title{
DIGITAL IMAGES ANALYSIS IN CORN SEEDLING EVALUATION
}

\author{
Author: EVERTON FELIX TEIXEIRA \\ Adviser: Prof. Dr. SILVIO MOURE CICERO \\ Co-Adviser: Prof. Dr. DURVAL DOURADO NETO
}

\section{SUMMARY}

The image analysis has high potential use in seed vigor determination. Associated to the seedlings growing test, this technique is fast, precise and makes possible the dimensional image analysis. The result is the total extension of each seedling quantifying the length of their constituent parts. With the purpose of studying the corn seed lots vigor through the seedlings growing test, using the digital images analysis, the corn seedlings (AG122 genotype) were taken from the germination chamber at the fourth day of development and ordered over a sheet, made with a transparent polyester film, on a scanner surface to the images capture. A routine was developed to process digital images of seedlings into the "Scil-Image" software. There was a computational procedure to measure the total length, with the usual sum of coleoptile to the main root length of seedling and also, not usually, to all root system. The seedlings were measured manually, seeking comparison with the method in study. The results showed that the digital technique makes possible association of the data obtained in processing to eventual vigor differences existing in corn seed lots, in a similar way to the other methods appointed to seed vigor evaluation by referred species. 


\section{INTRODUÇÃO}

Os testes de vigor têm sido amplamente divulgados e aceitos pela indústria de sementes como instrumentos para a tomada de decisões (Krzyzanowski \& Miranda, 1990; AOSA, 1983; Delouche, 1976).

Os testes de vigor devem complementar as informações obtidas no teste de germinação, que é desenvolvido sob condições controladas (Scott, 1978).

Conduzido de maneira similar ao teste padrão de germinação, o teste de crescimento de plântulas busca revelar a qualidade fisiológica de sementes, quanto à manifestação de seu vigor.

Existem pesquisadores que determinam o comprimento médio das plântulas normais ou de uma de suas partes, como a raiz primária, mas esses procedimentos, em função da morosidade e da subjetividade provocada pela falta de padronização para a retirada dos parâmetros, têm sido pouco utilizados (Edje \& Burris, 1970).

Dentro desse quadro, tem sido presenciada uma evolução favorável ao aperfeiçoamento de técnicas computadorizadas, mais sensíveis para a captação e mais precisas para o processamento e extração de informações úteis para a indústria de sementes, definindo-se uma amplificação de sensibilidade por vias digitais (Teixeira et al., 2003).

O presente trabalho de pesquisa teve por objetivo o desenvolvimento de uma sistemática de análise para a obtenção de medidas de plântulas de milho, com base na criação de uma rotina computacional na plataforma gráfica "ScilImage" e sua utilização no processamento de um banco de imagens digitais, para a medição instantânea e a obtenção de dados numéricos. 


\section{REVISÃO DE LITERATURA}

\subsection{Qualidade fisiológica de sementes}

Ao atingir um patamar comercialmente interessante, o uso de sementes necessitou da avaliação da qualidade do produto, como forma de assegurar as vendas. Hoje, por exigência de mercado, é notável a garantia dessa qualidade.

A utilização do teste de germinação para a avaliação da qualidade fisiológica das sementes foi consagrada ao longo do tempo como prática confiável para regulamentar sua comercialização. Atualmente, após constante aperfeiçoamento, chegou-se a níveis aceitáveis de reprodutibilidade e confiabilidade dos resultados obtidos (McDonald, 1993).

Sabe-se que as informações obtidas de um teste de germinação nem sempre podem predeterminar, com precisão, o desempenho das sementes em condições de campo, principalmente quando existe adversidade de condições (Ferguson, 1993).

Portanto, observando-se que alguns componentes de qualidade não estavam sendo avaliados de forma adequada pelo teste de germinação, isoladamente, e com necessidade de informações complementares sobre a qualidade de um lote de sementes, fez-se necessário o uso do conceito de vigor e de testes de laboratório para a sua avaliação (Krzyzanowski et al., 1999; Marcos Filho et al., 1987; Sá, 1987).

A ISTA - International Seed Testing Association (1981) considerou o vigor como sendo a soma das propriedades que determinam o potencial de atividade e desempenho da semente, ou do lote de sementes, durante a germinação e emergência das plântulas. 
A AOSA - Association of Official Seed Analysts (1983) definiu o vigor como o conjunto de propriedades que determinam o potencial para rápida e uniforme emergência e desenvolvimento de plântulas normais, sob diferentes condições ambientais.

Carvalho (1986) relatou que o vigor da semente pode ser entendido como o nível biológico de energia disponível para a realização das tarefas do processo germinativo.

Essa diversidade de definições evidencia as dificuldades, encontradas nas concepções, devidas à complexidade, a diversidade de propriedades que o termo abrange e à inexistência de grandeza referencial (Caliari \& Marcos Filho, 1990).

A maturidade fisiológica da semente pode ser considerada como o ponto de máximo peso de matéria seca, máxima germinação e máximo vigor. Esse é um momento de mínima deterioração e, desse ponto em diante, contudo, a evolução desta característica se faria de maneira semelhante à da germinação, isto é, tenderia a se manter no mesmo nível, ou decresceria, na dependência de fatores ambientais e do modo e momento da colheita (Carvalho \& Nakagawa, 2000).

A perda de germinação é um indicativo importante da perda de vigor, mas é a última conseqüência, o que torna útil o uso dos testes de vigor no monitoramento da qualidade de sementes durante a produção, processamento e armazenamento, pois a perda de vigor precede a perda de viabilidade. A maioria dos lotes comercializados encontra-se na fase inicial da curva de viabilidade, mas mesmo nessa faixa, a localização na curva de sobrevivência dependerá do estádio individual de deterioração e vigor (Custódio \& Marcos Filho, 1997).

O uso de vários testes para a avaliação do vigor de sementes ganha importância na medida em que, dependendo do método utilizado, as informações obtidas podem ser distintas entre si (Marcos Filho et al., 1987). 
No final da década de 30 , o teste de frio passou a ser utilizado para estimar o vigor de sementes de milho, baseando-se nos efeitos negativos da temperatura e alto teor de água do substrato sobre a emergência das plântulas. Esse teste tem sido utilizado em outros casos, considerando-se que, genericamente, sementes mais vigorosas sejam mais resistentes às condições desfavoráveis (Vieira \& Carvalho, 1994).

Para a avaliação do vigor de sementes de milho, também tem sido utilizado o teste do envelhecimento acelerado, baseado na premissa de que as sementes menos vigorosas perdem a capacidade de germinação mais rapidamente após o envelhecimento acelerado. Esse teste difere do teste de frio por apresentar maiores possibilidades no controle de variáveis e, assim, permite alcançar elevada padronização, tanto na metodologia de execução como na interpretação dos resultados (AOSA, 1983; Krzyzanowski \& Miranda, 1990).

O teste de condutividade elétrica da solução de embebição de sementes tem sido proposto como um teste para avaliar o vigor, uma vez que o valor da condutividade é função da quantidade de lixiviados na solução, a qual está diretamente relacionada com a integridade das membranas celulares, pois, membranas mal estruturadas e células danificadas estão, geralmente, associadas ao processo de deterioração da semente e, portanto, com sementes de baixo vigor (AOSA, 1983; Marcos Filho et al., 1987).

É possível que se avalie o crescimento das plântulas determinando o comprimento da plântula, ou de parte desta, através do teste de crescimento de plântulas, porém, autores como Irigon \& Rossini (1992) e Krzyzanowski et al. (1993) salientam a necessidade de padronização, em todos procedimentos com testes de vigor, para possibilitar a comparação de resultados (Nakagawa, 1999). Nesse sentido, sugere-se maiores estudos de metodologia, com objetivo de aprimoramento e obtenção de maiores subsídios para a padronização do teste de crescimento de plântulas (Barros \& Dias, 1992). 
Para a avaliação da qualidade fisiológica de sementes, métodos digitais têm sido recentemente propostos, sendo que, Keys et al. (1984) com base na medição do comprimento de partes de plântulas de soja, propuseram um sistema automático para a estimativa do vigor de sementes, denominado CASAS ("Computerized Automated Seed Analysis System").

McCormac et al. (1990), analisando imagens digitais de plântulas de sementes pequenas como a alface, a cenoura e a beterraba, propuseram uma alteração, via métodos digitais, na medição do comprimento do sistema radicular para o teste "slant-board" (prancheta inclinada) no propósito de aperfeiçoá-lo.

Sako et al. (2001), desenvolveram um sistema para indexar automaticamente o vigor de sementes a partir da análise computadorizada de imagens de plântulas de alface.

\subsection{Captação, processamento, reconhecimento e análise de imagens}

\subsubsection{Imagem padrão e imagem digital}

Uma imagem padrão em cores pode ser representada por uma função $C(x, y, t, A)$ em que $C$ representa a distribuição espacial de cor, nas coordenadas espaciais $\mathrm{x}$ e $\mathrm{y}$, ao tempo $\mathrm{t}$ e comprimento de onda $\mathrm{A}$. Uma imagem monocromática é representada pela função $C(x, y)$, pois é assumido que $A$ seja constante, sendo o tempo t, então, desconsiderado. Nesse caso, $x$ e y representam as coordenadas espaciais do ponto e $\mathrm{C}$ a intensidade ou o brilho, ou ainda, o nível de cinza para aquele ponto; portanto, uma imagem monocromática referencia apenas níveis de cinza (Gonzalez \& Wints, 1987).

Se imaginarmos um mosaico representado por unidades discretas e de formato bem conhecido como é o caso de um quadrado, conectadas uma a uma num plano, com endereçamento cartesiano e propriedades bem definidas, estaremos diante da representação pictórica em último pormenor de uma imagem. 
Portanto, toda imagem digital em duas dimensões (2D) obedece a um sistema de coordenadas espaciais $X Y$, onde são reconhecidos pontos, unidades discretas com atributos numéricos que denotam propriedades como a cor, sendo a representação da intensidade luminosa uma função $f(x, y)$ com valor proporcional ao brilho ou, no caso de imagens monocromáticas, níveis de cinza (Gonzalez \& Woods, 1992).

Uma imagem digital pode ser comparada a uma matriz, onde unidades discretas formadoras da imagem se dispõem em linhas e colunas, sendo que índices identificam um ponto na imagem e o seu correspondente atributo. As unidades discretas, formadoras da imagem são ditas elementos da imagem, do inglês "Pictures Elements" que foi abreviado para "Pics Els" e então fundido gerando o termo "Pixels".

\subsubsection{Resolução}

Uma imagem digital é definida por "pixels" e o que se pretende demonstrar com o uso do termo resolução de uma imagem digital é o seu arranjo espacial como o de uma matriz de "pixels" (i,j) formada por linhas e colunas. Como exemplo de resolução temos 1024 pls x 1024 pls (resolução vertical $x$ resolução horizontal), num plano formador de uma imagem totalizando 1.048.576 pls de resolução espacial, também chamado de tamanho da imagem ou definição. Como tamanhos típicos, temos usualmente 256×256 pls, 512×512 pls, $640 \times 480$ pls e $768 \times 512$ pls, sendo que câmeras digitais e "scanners" mapeiam tamanhos de 1600×1200 pls ou maiores (Gonzalez \& Wints, 1987).

Como as resoluções de captação (digitalização) e apresentação em tela são superiores aos tamanhos mais usuais, é comum a utilização de uma medida de resolução mais confiável, a densidade de resolução, onde são concentrados "pixels" por unidade de medida linear (Cruvinel et al., 1996).

Do inglês "dot" (ponto), temos que os pontos da tela do monitor de um computador são concentrados até um limite por unidade de medida fixa, a já consagrada polegada, originando o termo dpi ("dots per inch"), que define 
quantos pontos por polegada irão mapear uma cena até o limite máximo em tela (100\%), ou seja, seu nível de detalhamento visual.

Convencionou-se, por questões de correlação dimensional, que 100 "pixels" correspondem a 1 polegada $(2,54 \mathrm{~cm})$. Portanto, em escala centimétrica, temos 39,37 "pixels" (pls) em 1 centímetro $(39,37 \mathrm{pls} / \mathrm{cm}$ ou $1 / 39,37 \mathrm{~cm} / \mathrm{pls}$ ).

Esse detalhamento por pontos, ou seja, densidade de resolução espacial, interfere no número total de "pixels" de uma imagem exibida em tela, pois esse é um artifício utilizado para mapear uma cena com mais informações de atributos por unidade de medida. Sendo o "pixel" a parte elementar de uma imagem digital, resta ao computador transformar dpi extra em medidas extras, para exibir uma cena na tela, aumentando proporcionalmente as dimensões visuais da cena até o limite de resolução da imagem em tela, onde cada detalhe é formado por "pixels" em conexão (Teixeira et al., 2003).

Na Figura 1, observa-se com a ampliação da semente, feita da esquerda para a direita, que houve perda de resolução espacial por baixa densidade de pontos captados na operação de digitalização.

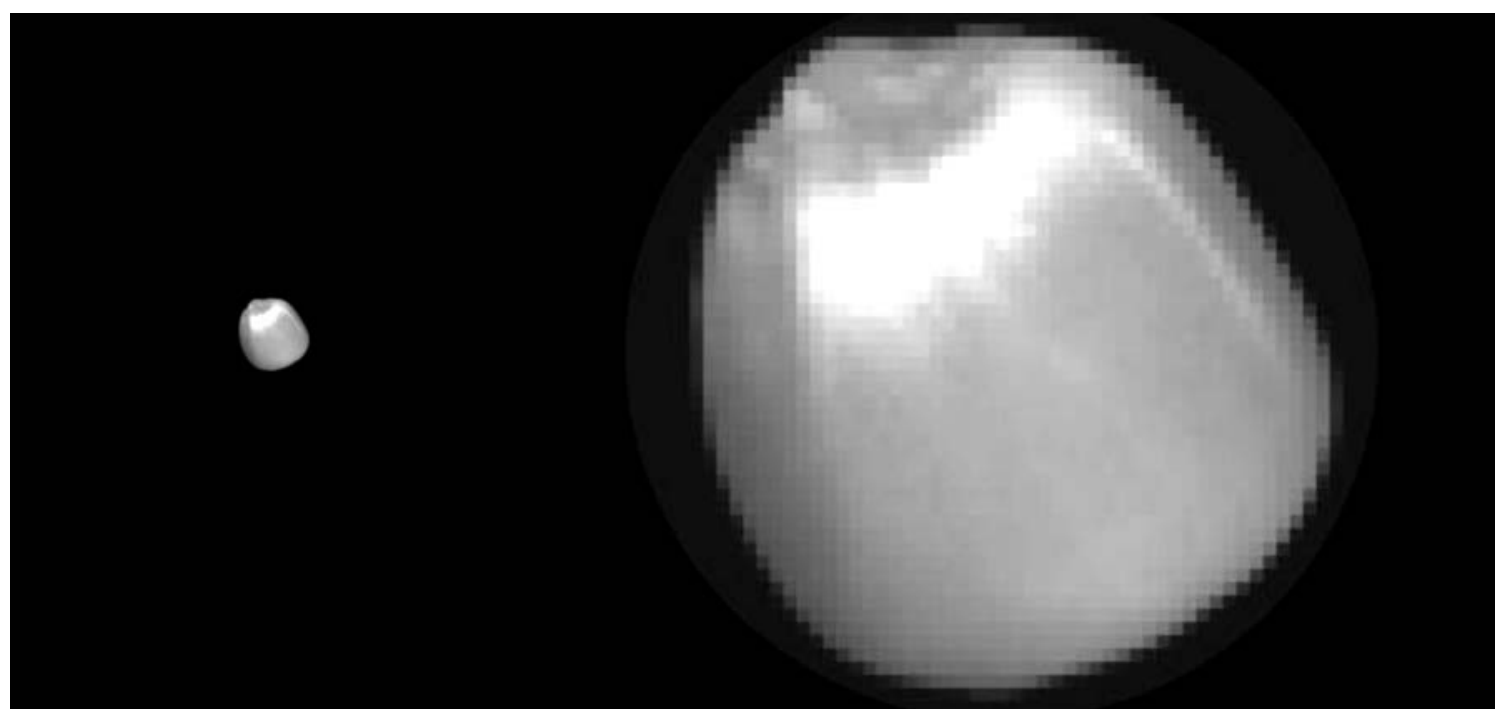

Figura 1 - Esquerda: semente de milho captada em imagem de 100 dpi, 256 tons de cinza e 8 bits. Direita: ampliada $7 x$ em tela (700\%) 
A dimensão original é mantida por regra de proporcionalidade, garantindo que, por exemplo, imagens com tamanho real de $3 \mathrm{~cm} \times 4 \mathrm{~cm}$, ou seja, ( $(3 \mathrm{~cm} x$ $39,37$ pixels $/ \mathrm{cm}=118,11 \mathrm{pls}) \times(4 \mathrm{~cm} \times 39,37 \mathrm{pixels} / \mathrm{cm}=157,48)) 18600 \mathrm{pls}$ totais em 100dpi x 100dpi, possam ser capturadas com 1200dpi x 1200dpi e, em seguida, ampliadas em proporções com grande número de pormenores em tela, para 12 vezes mais pontos (1200dpi $\times 1200 d p i)$, então, $(12 \times 118,11$ pls $=$ $1417,32$ pls $) \times(12 \times 157,48=1889,76$ pls $)$ que resultam numa malha de $1417,32 \times 1889,76=2.678 .394,6432$ pls totais mapeando uma área original de $12 \mathrm{~cm}^{2}$, numa imagem digital que poderá ser desdobrada em $(1417,32$ pls $x$ $1 / 39,37 \mathrm{~cm} / \mathrm{pls} \times 1889,76 \mathrm{pls} \times 1 / 39,37 \mathrm{~cm} / \mathrm{pls}=36 \mathrm{~cm} \times 48 \mathrm{~cm}) 1728 \mathrm{~cm}^{2}, \mathrm{em}$ escala 1:1 (100\%), num monitor que possibilite uma resolução de vídeo idêntica ou maior que a resolução de captação.

Procurar usar os arranjos quadráticos é importante quando se observa que as rotinas de processamento de imagens digitais são resoluções de matrizes, algoritmos que dependem da distribuição dos "pixels", para que o resultado final não produza rearranjos que distorçam características fundamentais da imagem, provocando uma desproporção na cena (Gonzalez \& Wints, 1987).

Mapeamentos com resoluções acima do limite de resolução de vídeo do monitor, quando em "zoom" de aproximação, mostrarão a cena com aumento de tamanho numa imagem com detalhamento crescente até o limite de resolução com o qual a imagem foi captada. A partir disso, existe a amostragem da imagem em tela com conseqüente perda de detalhes. O que se constata é um efeito de redução da resolução espacial, pela simulação da aproximação da cena (Figura 1).

Definição e resolução, juntas, visam tamanho e nível de detalhamento a serem mapeados e exibidos em uma imagem digital, mantendo intactas as informações relativas às dimensões e atributos originais da cena (Teixeira et al., 2003). 
Os enfoques da presente revisão são atributos dimensionais, tais como comprimento e área de objetos a serem destacados e extraídos de uma imagem digital, partindo-se da captação, processamento e análise.

\subsubsection{Captação}

A visão é considerada o sentido de maior eficiência de que se dispõe para o recebimento de informações. As cenas, ou arranjos de objetos no espaço tridimensional, que focamos são, quase que instantaneamente, convertidas em imagens e arquivadas em nossa memória.

Para se tentar automatizar o sentido da visão é que foram criados os sistemas de processamento de imagens. Assim, para se adquirir as imagens houve o desenvolvimento de aparelhos com sensores ópticos acoplados, que, como nos olhos humanos, permitem a leitura e a conversão da intensidade do sinal luminoso em sinal elétrico. Tais sensores são denominados de CCDs ("Charge-Coupled Devices"), enquanto que os conversores são denominados conversores A/D ("Analog to Digital Converts") (Ihrig \& Ihrig, 1997).

Captação ou digitalização de uma cena é a interpretação, por meio de sensores, da intensidade de sinais luminosos refletidos e sua conversão em dígitos binários para cada componente da imagem (Day, 1997).

Uma análise promissora dependerá fundamentalmente de uma digitalização adequada da cena. Tratando-se da luminosidade ambiente, um fenômeno comum é a formação de sombras, que formam imagens com diferentes formas e dimensões; outro, o excesso de luz, poderá incorrer em alterações rejeitáveis (Ihrig \& Ihrig, 1997).

McDonald et al. (2000), utilizando "scanners" para melhorar avaliações de sementes e plântulas, constataram que a captação de imagens tem o potencial de melhorar a padronização de testes em sementes. O mesmo potencial poderá ser constatado em aparelhos para o congelamento de cenas.

O tipo de digitalização tratado neste trabalho é o movimento congelado da cena ("Freezing motion"). Essa aplicação é capaz de ser produzida por 
aparelhos de captação tais como "scanners", câmeras fotográficas ópticas, câmeras fotográficas digitais e câmeras de vídeo com recursos de edição de gráficos quadro a quadro (Gonzalez \& Woods, 1992).

Uma imagem digital de baixa resolução mapeada em tela de alta resolução tem uma limitação prática, que consiste na perda de qualidade visual da cena quando pormenorizada através de zoom de aproximação. Ocorre que não havendo "pixels" extras para serem exibidos detalhando a imagem em tela, resta ao computador redesenhar "pixels" em amostras cada vez maiores de pontos para o recurso funcionar, obtendo-se, assim, uma cena com perda de detalhes, caracterizada por formas em cujos limites é observado um aspecto serrilhado, efeito da redução da resolução espacial (Day, 1997).

De outra maneira, se a resolução de captação for alta, essa amostragem resultará num mapeamento em resolução limite da tela com grandes dimensões. Sendo assim, ter-se-á uma imagem rica em detalhes, o que geralmente elimina a necessidade de "zoom" para maiores escalas de visualização, como exemplo, 2:1 ou $200 \%$.

\subsubsection{Processamento}

O processamento de uma imagem digital envolve várias operações que podem ser aplicadas aos dados de uma imagem (Figura 2). Nessas operações estão incluídas técnicas de compressão de imagens, restauração de imagens, melhoramento de imagens, quantificação, filtragem espacial, acabamento e reconhecimento (Teixeira et al., 2003).

Deve-se buscar, então, um programa onde possam estar reunidas rotinas de processamento e análise, com reconhecimento e interpretação de dados dimensionais em dados numéricos.

A plataforma "Scil-Image" dispõe de um grande número de ferramentas de processamento e análise de imagens, sendo utilizáveis através da elaboração de programações que, para serem aplicadas, dependerão da 
necessidade preliminar do usuário sobre o seu objeto de estudo e de sua prática em captar, isolar e enfocar o objeto a partir de uma determinada cena.

O processamento de imagens digitais envolve procedimentos que são comumente expressos na forma algorítmica (Gonzalez \& Wints, 1987). Dessa maneira, exceto a aquisição da cena e a sua posterior demonstração na forma digital, a maioria das funções de processamento deve estar presente num único programa, para que possam ser implementadas numa sistemática de trabalho.

Facon (1996) observou que existem várias teorias que buscam explicar o processamento de imagens pelo cérebro, sendo interessante considerar que o cérebro armazena dados para efetuar uma comparação entre a informação recebida e padrões de situações semelhantes arquivados.

Cicero (1994), em consideração ao processamento de imagens, concluiu que procedimentos puramente visuais têm provado serem subjetivos, imprecisos e ineficientes.

É considerada resolução de cor, o número de bits (b) utilizados para o armazenamento do vetor de cor de cada "pixel" da imagem, sendo que os níveis de cinza ( $L$ ) são estimados pela seguinte equação: $L=2^{\mathrm{b}}$ (McDonald \& Chen, 1990).

Uma imagem digital é geralmente composta com resoluções de cores variando de 8 a 24 bits, resultando em 256 níveis de cinza ou 16.777.216 cores, onde para maiores resoluções obtemos uma cena com melhores definições (Ihrig \& Ihrig, 1997). Com o processamento digital das cores de uma imagem, Howarth \& Stanwood (1993) avaliaram o vigor de sementes de milho partindo da instalação do teste de tetrazólio.

Foi convencionada a representação das cores em uma imagem digital com oito bits, em 256 níveis de cinza variando entre 0 e 255, sendo 0 (zero) a cor preta e 255 a cor branca (Facon, 1996). 


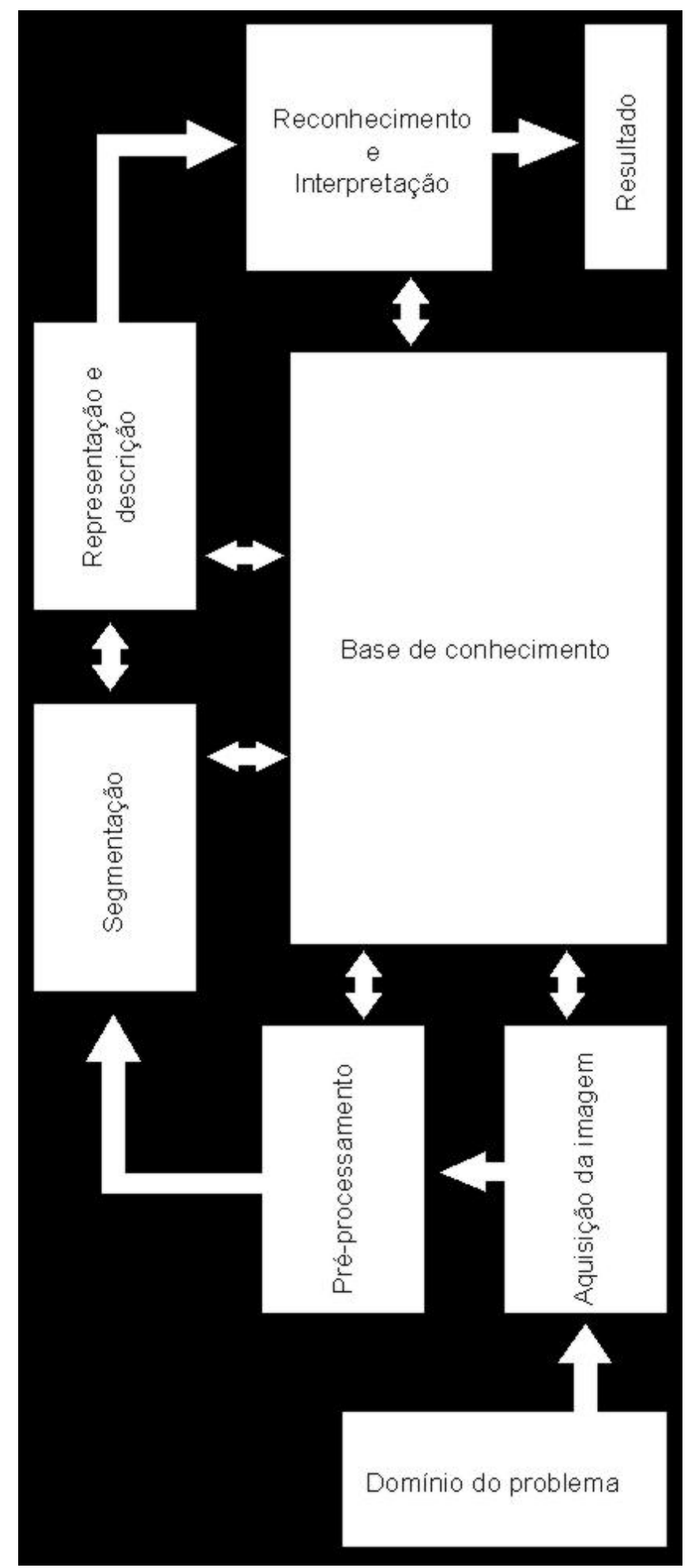

Figura 2 - Passos fundamentais no processamento de uma imagem digital Fonte: Gonzalez \& Woods, 1992 
Deve-se notar que uma maior resolução de cores implica em imagens que ocupam maior espaço físico no disco rígido, ou seja, arquivos com mais códigos, o que exige maior capacidade de gerenciamento (suporte do sistema), armazenamento (memória) e processamento do equipamento. Convém notar que uma imagem de 8 bits e 1024 x 1024 "pixels" requer um milhão de bytes (1MB) para armazenamento pós-captura (Gonzalez \& Woods, 1992).

No presente trabalho, são considerados apenas tratamentos que possam acrescentar soluções de processamento dimensional: a conversão, a binarização e a segmentação.

Cruvinel et al. (1996) citaram que em um trabalho de análise de imagens, criteriosamente, o processamento da imagem constitui-se em uma fase préprocessamento seguida pela análise propriamente dita.

$O$ pré-processamento consiste na melhoria da imagem de modo que aumentem as chances de sucesso em outros processos. Tipicamente, no préprocessamento lidamos com técnicas para melhoramento de contraste, remoção de ruídos e isolamento de regiões cuja textura indica uma semelhança de informações alfanuméricas (Gonzalez \& Woods, 1992).

Esse conjunto de técnicas não obrigatórias, mas muitas vezes necessárias (Vieira Júnior, 1998), permitem que sejam tratados e corrigidos defeitos e imperfeições que surgem numa imagem durante a digitalização da cena, em função de características do sistema e do ambiente (Facon, 1996).

\subsubsection{Conversão e segmentação}

Qualquer imagem digital, em cores ou monocromática pode ser convertida em um conjunto de códigos binários.

Um código binário é aquele que admite apenas duas situações, falso ou verdadeiro, representados em informática pelos números zero e um, que correspondem às cores branca e preta, respectivamente, sendo que para representações de outras cores ou níveis de cinza, são utilizadas combinações de 0 e 1 (Day, 1997). 
A conversão é uma técnica utilizada para se operar na simulação de figura e fundo numa imagem digital, transformando-se "pixels" selecionados para a cor branca, índice zero, e o restante de "pixels" para a cor preta, índice um. Com a conversão, pode-se selecionar objetos de interesse via segmentação, com filtros de limiar ("tresholding"), utilizados para detecção de descontinuidades da cena, ou seja, a fronteira dos objetos constituintes da imagem, com base na avaliação da cor de cada "pixel" (Jorge et al., 1996).

\subsubsection{Filtros e representações}

Filtros são recursos baseados na repetição de equações geométricas (iteração), em algoritmos usados para alterarem uma imagem, enquanto que é chamada representação a configuração final da cena após a imagem sofrer a ação de um ou mais filtros.

Filtros são ligados ao processamento de uma imagem de tal modo que a informação relevante seja mais bem exposta (melhoramento da imagem), sendo usados para suprimir ruídos da imagem, remover sombreamentos, melhorar ligações entre "pixels" num objeto, reforçando-as ou destruindo-as.

Existem ainda filtros de morfologia que, com base na detecção de limiares ("tresholding"), são utilizados para alterar ou reforçar detalhes em cena, sendo eles o filtro de erosão e o filtro de dilatação. Essas alterações geram diferentes representações de um objeto em uma cena, dando possibilidade para inferências quantitativas relativas a área. Por outro lado, a formação do esqueleto é uma operação utilizada para descrever as porções medianas de um objeto em cena, a partir de extremidades definidas, possibilitando inferências quantitativas relativas a dimensão linear (Gonzalez \& Woods, 1992).

Sako et al. (2001), valendo-se de algoritmos para detecção de limiar ("tresholding") e esqueletização, desenvolveram um sistema para indexar automaticamente o vigor de sementes a partir da análise de imagens de plântulas de alface. 


\subsubsection{Reconhecimento e análise de imagens}

A análise de imagens digitais pelo processamento gráfico consiste no reconhecimento da cena para a geração de características dimensionais, como áreas ou comprimentos de objetos, ou atributos, como padrões de cores e texturas, e a sua mensuração através de métodos de contagem ou freqüência de "pixels" (Vooren \& Heijden, 1993).

Para o processamento gráfico, foram desenvolvidos algoritmos de computação, que devidamente sistematizados são a base para a análise de imagens digitais, que poderá ser caracterizada pelo arquivamento de dados e, ou, comparação de padrões. Kranzier (1985) dividiu o processamento de imagens digitais em três categorias: análise de imagens, visão robótica e inspeção.

Cicero et al. (1998) utilizaram uma técnica combinada de obtenção de imagens por raios- $X$ e processamento digital de imagens, para analisar os efeitos de danos mecânicos internos e externos em sementes de milho.

Geralmente os algoritmos presentes em programas computacionais iniciam a leitura dos "pixels" de uma imagem pelo seu canto inferior esquerdo, até que encontram o primeiro "pixel" em conexão, ou seja, o primeiro "pixel" do primeiro objeto em análise; a esse "pixel" é atribuído o valor 1, como uma etiqueta, e aos outros "pixels" constituintes do objeto o valor 2. Assim, em leituras repetidas, outros objetos vão sendo mapeados com valores sucessivos, obtendo-se o reconhecimento da imagem (Gonzalez \& Woods, 1992).

McDonald \& Chen (1990) relataram que, além da utilização em agrometeorologia, a análise de imagens vem sendo adaptada para a análise de formas e dimensões de objetos contidos em uma cena.

Alguns autores, como Vooren \& Heijden (1993), valeram-se da análise de imagens digitais na agricultura para a determinação das dimensões de órgãos de uma planta. 
Dentro da área da tecnologia de sementes, Gunasekaran et al. (1988) avaliaram danos provocados por patógenos em sementes de soja e milho. Zayas et al. (1990) avaliaram danos mecânicos em sementes de milho.

Vieira Júnior (1998) utilizou a técnica de análise de imagens digitais definindo parâmetros e procedimentos necessários, relativos à viabilização do emprego de um protocolo, para a determinação do comprimento e da largura de sementes de milho. 


\section{MATERIAL E MÉTODOS}

\subsection{Material}

O presente trabalho de pesquisa foi conduzido nas dependências do Laboratório de Análise de Imagens e do Laboratório de Análise de Sementes, situados no Departamento de Produção Vegetal da Escola Superior de Agricultura "Luiz de Queiroz" - Universidade de São Paulo, Piracicaba, estado de São Paulo.

Utilizaram-se sementes de um único genótipo de milho, AG122, peneira 22/64" $(0,870 \mathrm{~cm})$ provenientes de cinco lotes com potencial fisiológico distinto.

Utilizou-se uma estação gráfica com microprocessador P4 (Pentium 4), com 1 Ghz, 256 Mb de RAM em plataforma Windows 2000.

As plântulas foram digitalizadas em um "scanner" profissional de superfície, marca UMAX, modelo PowerLook 1100, onde foram feitas as tomadas das cenas. Utilizaram-se folhas tamanho A4, de poliéster transparente, como base para a disposição e arranjo das plântulas na área de digitalização.

O programa "Photoshop" foi utilizado para o preparo das imagens de plântulas com a raiz principal e coleóptilo, partindo-se das imagens originais.

A plataforma gráfica "Scil-Image" foi utilizada para a construção e implementação da rotina para o processamento gráfico das imagens digitais, com a finalidade de se obter resultados de medidas relativas ao desenvolvimento, como o comprimento do sistema radicular e o da parte aérea.

Após a emissão dos relatórios com os resultados obtidos pelo processamento, utilizou-se a planilha de cálculos "Microsoft Excel" para a 
conversão das medidas quantificadas em "pixels" para dados em centímetros, como alternativa para melhor familiarização com os resultados obtidos.

\subsection{Métodos}

\subsubsection{Teste de crescimento de plântulas}

Para determinação da qualidade fisiológica das sementes, a qual está em íntima dependência do seu estado de vigor, foi utilizado o teste de crescimento de plântulas (Nakagawa, 1994).

O teste foi realizado em rolos de papel para germinação. Para o preparo do rolo foram utilizadas três folhas de papel toalha "germitest" distribuídas, duas sob as sementes e uma cobrindo-as. A umidade do papel substrato foi padronizada para duas e meia vezes a sua massa.

Foram semeadas dez sementes por rolo, dispostas em linha no terço superior do papel pré-umedecido, em sentido longitudinal, tomando-se cuidado com o espaçamento entre elas.

De cada um dos cinco lotes foram tomadas quatro repetições (ou subamostras) de cinqüenta sementes, sendo assim, duzentas sementes preenchendo vinte rolos por lote em estudo.

Os rolos foram agrupados quatro a quatro com atílios de borracha e, então, dispostos em sacos plásticos e fechados, visando manter constante a umidade no interior das embalagens (Krzyzanowski, 1991).

A extremidade superior dos rolos esteve distanciada de, ao menos, quinze centímetros da abertura do saco, para permitir o desenvolvimento das plântulas. Dessa maneira, os rolos foram colocados em pé em germinadores com temperatura regulada para $25^{\circ} \mathrm{C} \pm 1^{\circ} \mathrm{C}$, e ausência de luz.

Ao quarto dia de desenvolvimento no germinador foram quantificadas, de acordo com as Regras para Análise de Sementes (Brasil, 1992), as plântulas normais, anormais e sementes mortas. Via manual, com o auxílio de uma régua graduada em centímetros, foram medidos o comprimento da maior raiz e o 
comprimento do coleóptilo, totalizando-se as medidas das plântulas normais (maior raiz mais parte aérea) para cada uma das quatro repetições de sementes por lote, inicialmente semeadas.

\subsubsection{Digitalização da imagem}

Todas as plântulas normais de cada um dos cinco lotes foram digitalizadas, visando o processamento gráfico para análise das imagens com a obtenção de medidas via computação.

Para o preparo das cenas, ou seja, disposição dos objetos na área de digitalização, as plântulas de milho foram ordenadas sobre uma folha de poliéster transparente (transparência para escrita manual), tamanho A4 (210 mm x 297 mm) na superfície do "scanner" para a captação das imagens.

Cada uma das plântulas foi arranjada com o auxílio de uma pinça, partindo-se da disposição da face dorsal do resíduo da semente sobre a superfície do "scanner", inserida logo abaixo da linha que corta o primeiro terço da folha de poliéster (70 mm x $297 \mathrm{~mm}$ ) com um gabarito riscado sobre uma folha de PVA ou cartolina no tamanho A4, colocado sob a transparência.

Considerou-se o paralelismo entre plântulas, evitando-se a interferência de partes como raízes de um mesmo sistema radicular ou de sistemas radiculares distintos que pudessem se encostar. O mesmo cuidado foi considerado para os coleóptilos, impedindo-os que se encostassem.

O tipo de digitalização utilizado foi o movimento congelado da cena ("freezing motion"). A tampa do "scanner" não foi fechada em momento algum.

Para a captura ou digitalização, o programa do "scanner" foi ajustado para a leitura da cena em uma imagem com as seguintes características: formato A4, 256 tons de cinza mapeados em 8 bits, 300 dpi $\times 300$ dpi de densidade de resolução de captura, em leitura ajustada para modo refletivo.

Após a formação da imagem, automaticamente, fez-se a sua compressão para o modo gráfico JPEG e seu arquivamento. Assim, criou-se um banco de imagens digitais do tipo JPEG em formato A4 (210 mm x $297 \mathrm{~mm})$. 
Com a posse de todas as imagens relativas às plântulas em estudo, passou-se para a fase informatizada de coleta de dados.

\subsubsection{Processamento}

Desenvolveu-se uma rotina computacional, em linguagem de comandos "macro", na plataforma gráfica "Scil-Image", para o processamento e a análise das imagens digitais, com a finalidade de se obter resultados de medidas relativas ao desenvolvimento.

O banco composto por duzentas imagens foi acessado e a rotina carregada no módulo "macro" onde, com o comando "ok" clicado, houve a ação da rotina sobre cada imagem original.

Em passo imediato e subseqüente, houve medição computadorizada da extensão total, com a soma usual do comprimento do coleóptilo ao comprimento da maior raiz de cada plântula e, também, utilizou-se a rotina para o processamento e análise não usual, do comprimento do coleóptilo somado ao de todo sistema radicular.

As medidas resultantes foram então convertidas de "pixels" para centímetros, de acordo com a equação abaixo, e assim estudadas estatisticamente.

$$
\underline{C n}=r \cdot \frac{2,54 \cdot 10^{-4}}{n} \cdot \sum_{i=1}^{n} c_{i}
$$

Em que $\underline{C n}$ se refere à média aritmética, em centímetros, dos $\mathrm{n}$ comprimentos (c) dos objetos (plântulas) obtidos em "pixels" sob resolução (r) dada em dpi. 


\subsubsection{Teor de água da semente}

O teor de água da semente foi determinado pelo método padrão de estufa a $105 \pm 3^{\circ} \mathrm{C}$ por 24 horas (Brasil, 1992). Calcularam-se os resultados com base no peso úmido $(\mathrm{Bu})$, os quais foram expressos em percentagem.

\subsubsection{Teste de germinação}

$\mathrm{Na}$ avaliação da germinação, seguiram-se os critérios estabelecidos pelas Regras para Análises de Sementes (Brasil, 1992).

Ao acaso, duzentas sementes de cada um dos cinco lotes foram divididas em quatro repetições de cinqüenta sementes.

Como substrato, utilizaram-se rolos de três folhas de papel "germitest" umedecidos com água equivalente a duas e meia vezes o seu peso.

O germinador foi regulado a $25^{\circ} \mathrm{C}$, no escuro, com os rolos deixados em pé no seu interior. Com quatro dias de desenvolvimento foi feita a primeira contagem e a contagem final no sétimo dia.

\subsubsection{Teste de envelhecimento acelerado}

Para a realização deste teste, foram utilizadas quatro repetições de cinqüenta sementes para cada um dos cinco lotes em estudo.

As sementes foram dispostas dentro de caixas plásticas de germinação em camadas simples e uniformes sobre telados de aço inox encaixados acima de volumes de $40 \mathrm{ml}$ de água deionizada e mantidos em incubadora BOD sob $41^{\circ} \mathrm{C}$ e $100 \%$ de umidade relativa do ar por 96 horas (Marcos Filho, 1999).

Após esse período, as sementes foram conduzidas ao germinador de modo semelhante ao descrito para o teste de germinação para a avaliação das plântulas em conformidade com as Regras para Análise de Sementes (Brasil, 1992). 


\subsubsection{Teste de condutividade elétrica}

Utilizaram-se quatro repetições de cinqüenta sementes por lote, pesadas e embebidas em $75 \mathrm{~mL}$ de água deionizada dentro de copos plásticos por 24 horas sob $25^{\circ} \mathrm{C}$ (Vieira \& Krzyzanowski, 1999).

Passado esse período de embebição foram realizadas, em condutivímetro da marca DIGIMED, Modelo DM-31, as leituras cujos valores determinados foram divididos pelas massas relativas às cinqüenta sementes $\mathrm{e}$ expressos em termos de $\mu \mathrm{mho} . \mathrm{cm}^{-1} \cdot \mathrm{g}^{-1}$.

\subsubsection{Teste de Frio}

Para a condução do teste de frio, houve quatro repetições de cinqüenta sementes por lote semeadas em caixas plásticas, para cada repetição, sobre três quilogramas de mistura de areia e terra na proporção 3:1 e cobertas com um quilograma restante.

A quantidade de água adicionada em cada caixa (392 mL) foi o ajuste para $70 \%$ da capacidade de saturação da mistura de areia e terra, sendo distribuída uniformemente por toda superfície na caixa, logo embalada em saco plástico, vedando-se a abertura do saco com fita adesiva (Barros et al., 1999).

As caixas permaneceram por sete dias em câmara fria a $10^{\circ} \mathrm{C}$, sendo que, após esse período, foram desembaladas e transferidas para uma câmara com temperatura de $25^{\circ} \mathrm{C}$ de onde, ao sétimo dia, houve sua retirada para avaliação das plântulas normais emergidas (Krzyzanowski et al., 1991; Barros et al., 1999).

\subsubsection{Análise estatística dos resultados}

As plântulas provenientes do teste de crescimento foram medidas manualmente, buscando-se comparação com o método de processamento digital proposto para a obtenção dos comprimentos. Todas as médias foram obtidas incluindo-se as plântulas normais, plântulas anormais e sementes 
mortas no espaço amostral relativo a cada lote, partindo-se de duzentas sementes por lote.

Paralelamente foram feitas as análises do teste de germinação, teste de condutividade elétrica, teste de envelhecimento acelerado e teste de frio, aplicados aos cinco lotes em estudo para a comparação de seus resultados aos obtidos no teste de crescimento das plântulas.

Todos os testes foram envolvidos em análises estatísticas distintas com quatro repetições em delineamento inteiramente casualizado realizado no sistema SANEST (Zonta \& Machado, 1984), sendo que, as médias obtidas foram comparadas pelo teste de Tukey com diferença mínima significativa situada em 5\% de probabilidade. Assim, o potencial fisiológico de cada lote avaliado pelas análises dos testes paralelos foi comparado com as respostas do teste de crescimento de plântulas, obtidas via manual e digital.

Posteriormente, visando-se uma interpretação mais abrangente dos dados obtidos em todos os testes, utilizou-se a classificação estatística (Martins \& Silva, 2004) dos lotes sendo que, em cada teste, atribuiu-se a cada um dos lotes a pontuação resultante do somatório das pontuações positivas ou nulas (número de lotes estatisticamente inferiores) e negativas ou nulas (número de lotes estatisticamente superiores).

Assim, a soma dos valores obtidos em todos os testes constituiu a pontuação geral do lote para cada um dos conjuntos $A$ e $B(A=$ condutividade elétrica (CE), envelhecimento acelerado (EA) e teste de frio (TF) e $B=C R P m$ (coleóptilo mais raiz principal via medição manual), CRPp (coleóptilo mais raiz principal via processamento), CSRp (coleóptilo mais sistema radicular via processamento)).

Obtidos os números de lotes presentes em grupos idênticos nos conjuntos A e B de testes, calculou-se a taxa (\%) de coincidência (TC = número total de lotes presentes no mesmo grupo . número total de lotes ${ }^{-1}$.100) para relacionar os resultados dos testes dos conjuntos A e B (Martins \& Silva, 2004). 


\section{RESULTADOS E DISCUSSÃO}

Seguem registradas as avaliações que são a base para a aplicação de alguns conceitos sobre processamento de imagens digitais, considerando-se um procedimento para a análise dimensional durante o teste de crescimento de plântulas, orientado ao controle de qualidade em produção de sementes.

Para a correta avaliação da qualidade dos lotes é importante que, conjuntamente com os resultados obtidos pelo teste de crescimento de plântulas, considere-se a porcentagem de germinação, pois podem ocorrer situações em que as poucas plântulas normais formadas, incorrendo em baixa percentagem de germinação, apresentem alta taxa de crescimento, fato que não poderá ser transposto para toda amostra ou todo o lote, considerando-o vigoroso (Nakagawa, 1994).

\subsection{Qualidade dos lotes}

Examinando-se os resultados relativos ao teor de água das sementes dos cinco lotes em estudo (Tabela 1), observou-se que houve valores semelhantes. Cabe ressaltar que a uniformização do teor de água das sementes é indispensável à padronização, para que se possa prosseguir com os testes e suas avaliações (Marcos Filho et al., 1987).

O teste de germinação (Tabela 1 ) indicou resultados semelhantes, com as sementes dos cinco lotes do cultivar AG122 apresentando alta germinação, não caracterizando diferenças exeqüíveis quanto à emissão de estruturas essenciais dos embriões que se desenvolveram durante as avaliações.

Diferenças na qualidade fisiológica dos lotes testados puderam ser 
identificadas através das informações adicionais ao teste de germinação, geradas pelos testes apresentados a seguir.

O teste de envelhecimento acelerado (Tabela 1 ), visando o fornecimento de um parâmetro de qualidade fisiológica mais sensível que o teste de germinação (Marcos Filho, 1999), promoveu uma classificação mais consistente dos lotes em termos de potencial de desempenho, separando o lote $1 \mathrm{com}$ sementes de maior potencial fisiológico do lote 2, com sementes de menor potencial fisiológico. Os resultados apontaram para uma semelhança entre os lotes 3, 4 e 5, que não puderam ser caracterizados como lotes de sementes de potencial fisiológico intermediário pelo teste de envelhecimento acelerado estando, a critério, no conjunto de lotes com sementes de maior potencial fisiológico ou no conjunto de lotes de sementes com menor potencial fisiológico devido a não existência de diferença estatisticamente significativa entre as grandezas avaliadas nos lotes 3, 4 e 5 em relação ao lote 1 ou ao lote 2.

Através do teste de condutividade elétrica (Tabela 1), foi possível a categorização dos lotes em três níveis de vigor, assim, o lote 1 foi considerado como de maior potencial fisiológico, os lotes 3 e 4 foram considerados como de potencial fisiológico intermediário, enquanto que na categoria de menor potencial fisiológico, incluiu-se o lote 2. De acordo com o teste de condutividade elétrica, o lote 5 não apresentou diferença para uma categorização mais precisa entre o potencial fisiológico intermediário e o de menor potencial fisiológico.

O teste de frio (Tabela 1) possibilitou a classificação das sementes dos lotes 1 e 4 como sementes de maior potencial fisiológico e das sementes do lote 2 como de menor potencial fisiológico. Houve semelhança de potencial fisiológico entre o lote 3 e os lotes 1 e 4, considerados de maior potencial fisiológico e outra semelhança de potencial fisiológico entre o lote 5 e o lote 2 , considerado como de menor potencial fisiológico, o que demonstrou que os lotes 3 e 5 não são, seguramente, caracterizáveis como lotes de potencial fisiológico intermediário. 
Tabela 1. Qualidade das sementes dos cinco lotes analisados, avaliada inicialmente, onde se observa: teor de água (TA), teste de germinação (TG), condutividade elétrica (CE), envelhecimento acelerado (EA) e teste de frio (TF)

\begin{tabular}{cccccc}
\hline Lote & TA & TG & EA & CE \\
$(\%)$ & $(\%)$ & $(\%)$ & $\begin{array}{l}\text { TF } \\
(\%)\end{array}$ \\
\hline & $9,0 \mathrm{a}^{*}$ & $99,5 \mathrm{a}$ & $98,5 \mathrm{a}$ & $8,73 \mathrm{a}$ & $96,0 \mathrm{a}$ \\
2 & $8,9 \mathrm{a}$ & $99,5 \mathrm{a}$ & $82,5 \mathrm{~b}$ & $14,75 \mathrm{c}$ & $82,5 \mathrm{c}$ \\
3 & $9,0 \mathrm{a}$ & $96,5 \mathrm{a}$ & $90,0 \mathrm{ba}$ & $11,87 \mathrm{~b}$ & $93,5 \mathrm{ba}$ \\
4 & $9,1 \mathrm{a}$ & $96,5 \mathrm{a}$ & $90,5 \mathrm{ba}$ & $12,83 \mathrm{~b}$ & $95,5 \mathrm{a}$ \\
5 & $8,9 \mathrm{a}$ & $98,8 \mathrm{a}$ & $88,5 \mathrm{ba}$ & $13,14 \mathrm{bc}$ & $84,5 \mathrm{bc}$ \\
$\mathrm{CV}(\%)$ & 0,89 & 1,55 & 6,36 & 5,57 & 7,09 \\
\hline
\end{tabular}

"Médias, nas colunas, seguidas de mesma letra não diferem entre si pelo teste de Tukey a 5\% de probabilidade

\subsection{Potencial fisiológico através do teste de crescimento de plântulas}

\subsubsection{Análise manual}

Sementes vigorosas originam plântulas com maior taxa de crescimento, em função de apresentarem maior capacidade de transformação e de suprimento de reservas dos tecidos de armazenamento e da maior incorporação destes pelo eixo embrionário (Dan et al., 1987).

A avaliação dos resultados obtidos com a medição manual das plântulas de milho (Figura 3) oriundas dos cinco lotes de sementes do genótipo AG122, indicou que, de acordo com a soma do coleóptilo com a maior raiz em cada plântula normal (Barros \& Dias, 1992; Nakagawa, 1999) totalizada em termos de média aritmética para cada lote (Figura 14), houve a possibilidade de categorização dos lotes em dois níveis de vigor (Tabela 3). 
Tal categorização inclui as sementes do lote 1 em um nível considerado como de maior potencial fisiológico, enquanto que os lotes 2 e 5 foram inclusos no nível considerado como o de sementes de menor potencial fisiológico.

Ainda, os resultados apontaram para uma semelhança entre os lotes $3 \mathrm{e}$ 4 não precisamente categorizada, podendo esses ser inclusos, com o estabelecimento de critério auxiliado pelos resultados dos outros testes, na classificação de lotes de maior potencial fisiológico ou na classificação de lotes de menor potencial fisiológico, devido a não existência de diferença entre as duas grandezas avaliadas nos lotes 3 e 4 em relação aos lotes 1, 2 e 5, o que impossibilitou uma separação com categorização de maior amplitude.

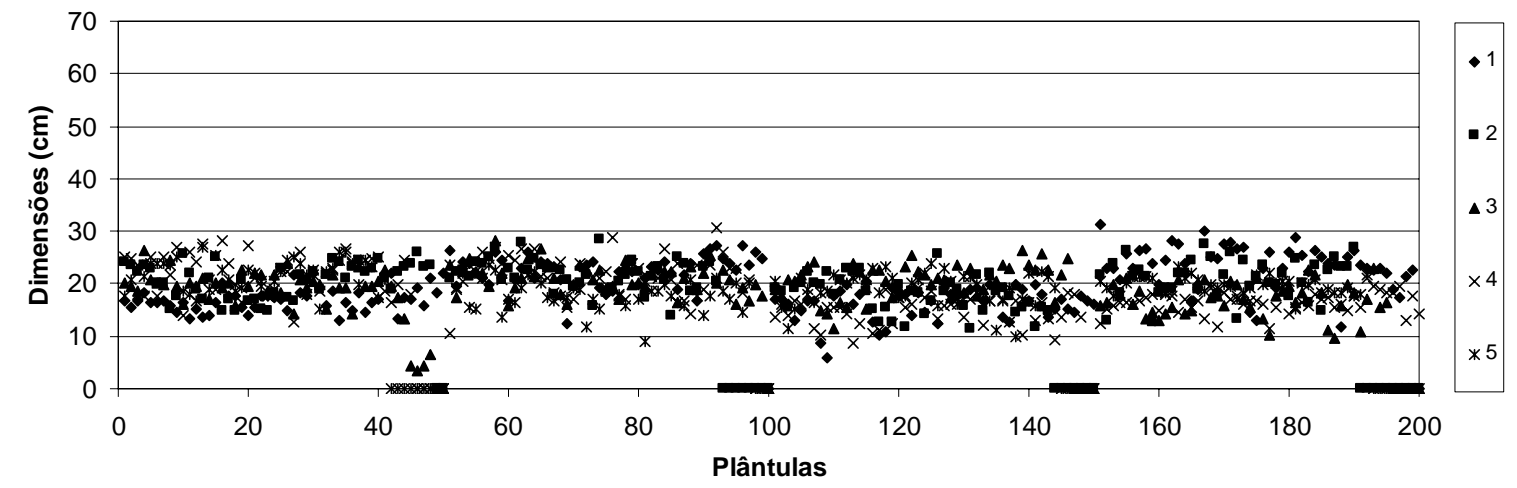

Figura 3 - Dados do procedimento manual de medição usual do comprimento do coleóptilo mais a raiz principal (CRPm) de plântulas dos cinco lotes, em amostras de duzentas sementes inicialmente semeadas

\subsubsection{Análise pelo processamento de imagens digitais}

A pesquisa resultou na construção da rotina computacional (Tabela 2) nomeada EFT_SkiLLMeasure versão 3.3, que faz o processamento e a análise dimensional de plântulas intactas de milho em imagens digitais, para a geração de dados numéricos relativos ao comprimento da parte aérea somada ao sistema radicular na plataforma gráfica "Scil-Image". 
A captação das imagens em "scanner" foi uma ação importante que envolveu detalhes simples de disposição das plântulas no formato orientado com o eixo cartesiano, alinhadas paralelamente com o menor lado da imagem e também entre si, sem que se encostassem.

O não fechamento da tampa do "scanner" e a não iluminação diretamente sobre 0 aparelho durante $\mathrm{o}$ procedimento de digitalização produziram o efeito de fundo desejado para a formação das imagens com o preto (1) como cor predominante.

Este conjunto de procedimentos iniciais foi imprescindível ao desempenho da análise devido a propriedades fundamentais da imagem como, disposição orientada no eixo cartesiano, alto contraste entre objetos e fundo e não interferência entre os limites dos objetos, necessárias para a performance na computação gráfica (Teixeira et al., 2003).

Foram obtidas imagens leves (Figuras 4, 5, 6, 7 e 8) que apresentavam as especificações de cor em 256 tons de cinza, com mapeamento de 8 bits por elemento de imagem ("pixel") para a expressão das variações de 256 tons de cinza compreendidos entre o branco (0) e o preto (1) e 300 dpi X 300 dpi de resolução espacial.

Uma vez acessadas as imagens digitais na plataforma "Scil-Image", utilizou-se a programação (Tabela 2) que, ao funcionar com cada uma das duzentas imagens obtidas, analisou e gravou em relatório a dimensão comprimento requerida pelo processamento.

A rotina computacional EFT_SkiLLMeasure versão 3.3 agiu convertendo a imagem para o modo binário, detectando limiares dos objetos, etiquetando todos objetos presentes em cena, eliminando pequenos objetos tecnicamente denominados de interferências, dilatando e erodindo as representações das plântulas para a retomada de algumas conexões que, por ventura, pudessem estar mascaradas por sombreamento provocado durante a captação (Teixeira et al., 2003). 
O próximo passo da rotina foi a transformação das plântulas da representação anterior em esqueletos de "pixels" minimamente conectados, formando segmentos finíssimos, em preparação para a medição. Na seqüência, o algoritmo denominado contador de "pixels" foi utilizado (Figura 9).

Pareceu insuperável a questão das mensurações de segmentos visualmente curvos, naturalmente formados nos esqueletos, tanto para coleóptilos como para raízes.

Ocorre que a conectividade dos "pixels" esconde seu padrão geométrico individual, ou seja, o quadrado que, em última escala visual, tornou possíveis os cálculos matemáticos para as figuras complexas. Na resolução desta questão foi utilizada a lógica fractal. 


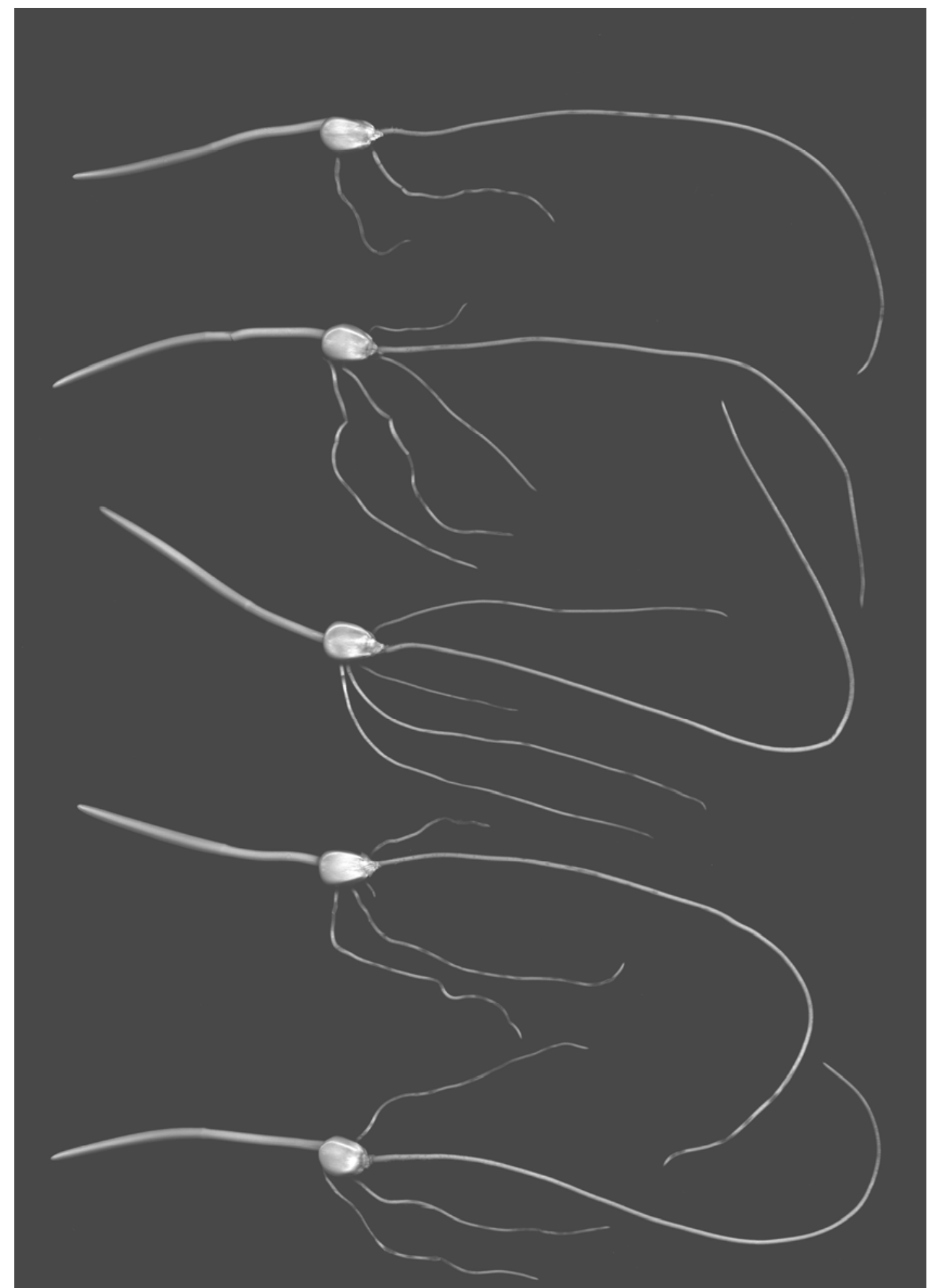

Figura 4 - Imagem digital amostrada do lote 1, pronta para a análise com o uso da rotina de processamento 


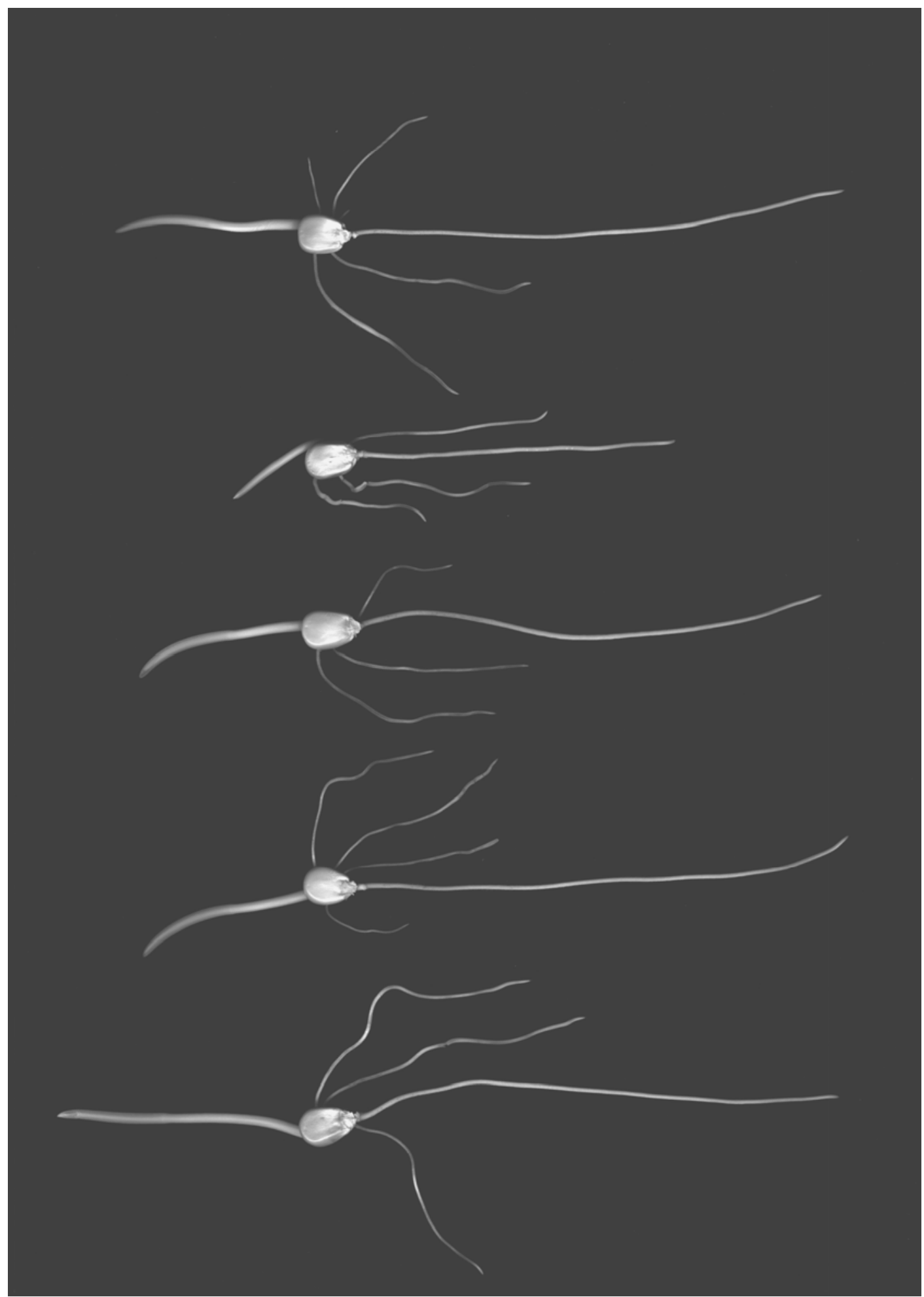

Figura 5 - Imagem digital amostrada do lote 2, pronta para a análise com o uso da rotina de processamento 


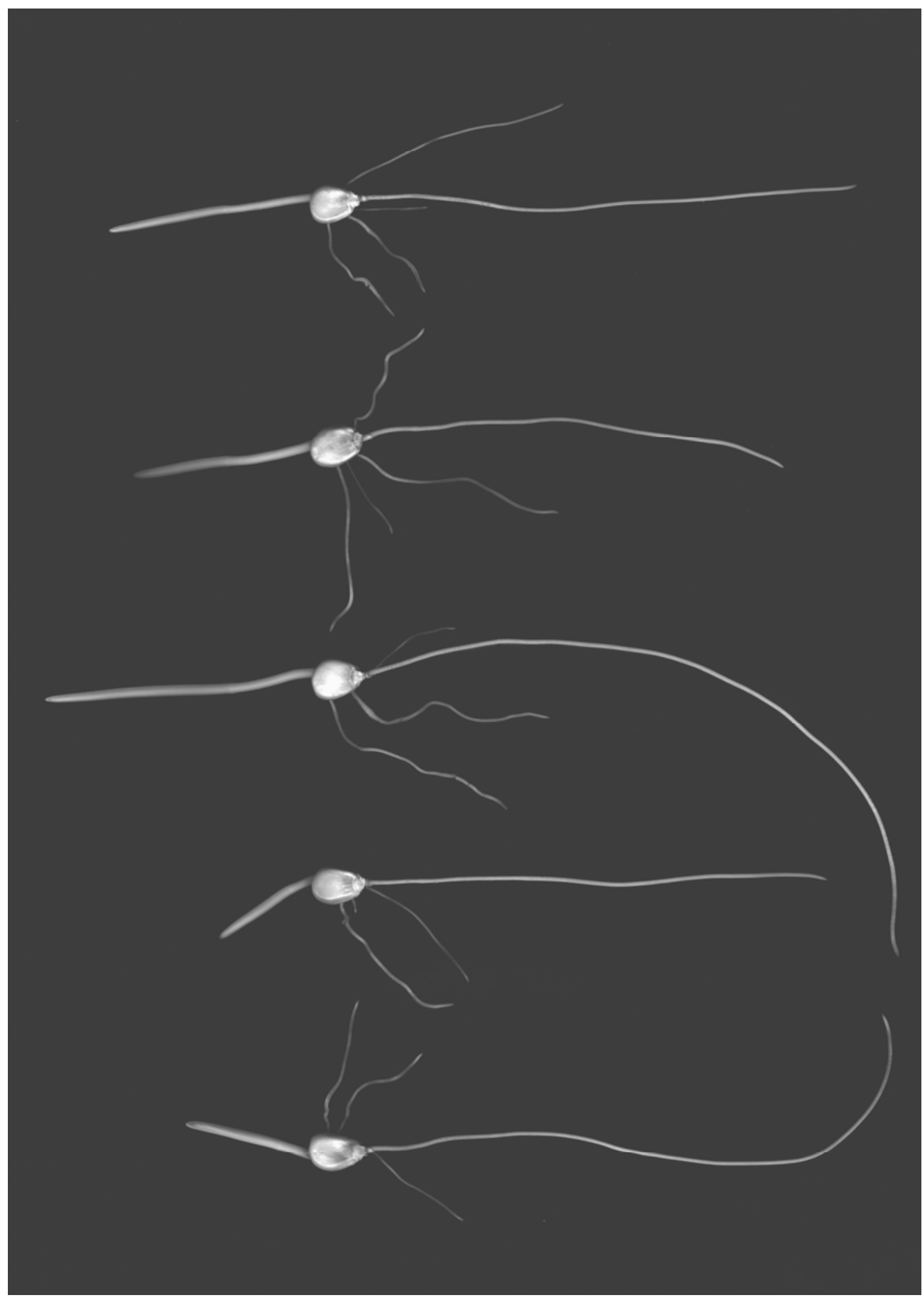

Figura 6 - Imagem digital amostrada do lote 3, pronta para a análise com o uso da rotina de processamento 


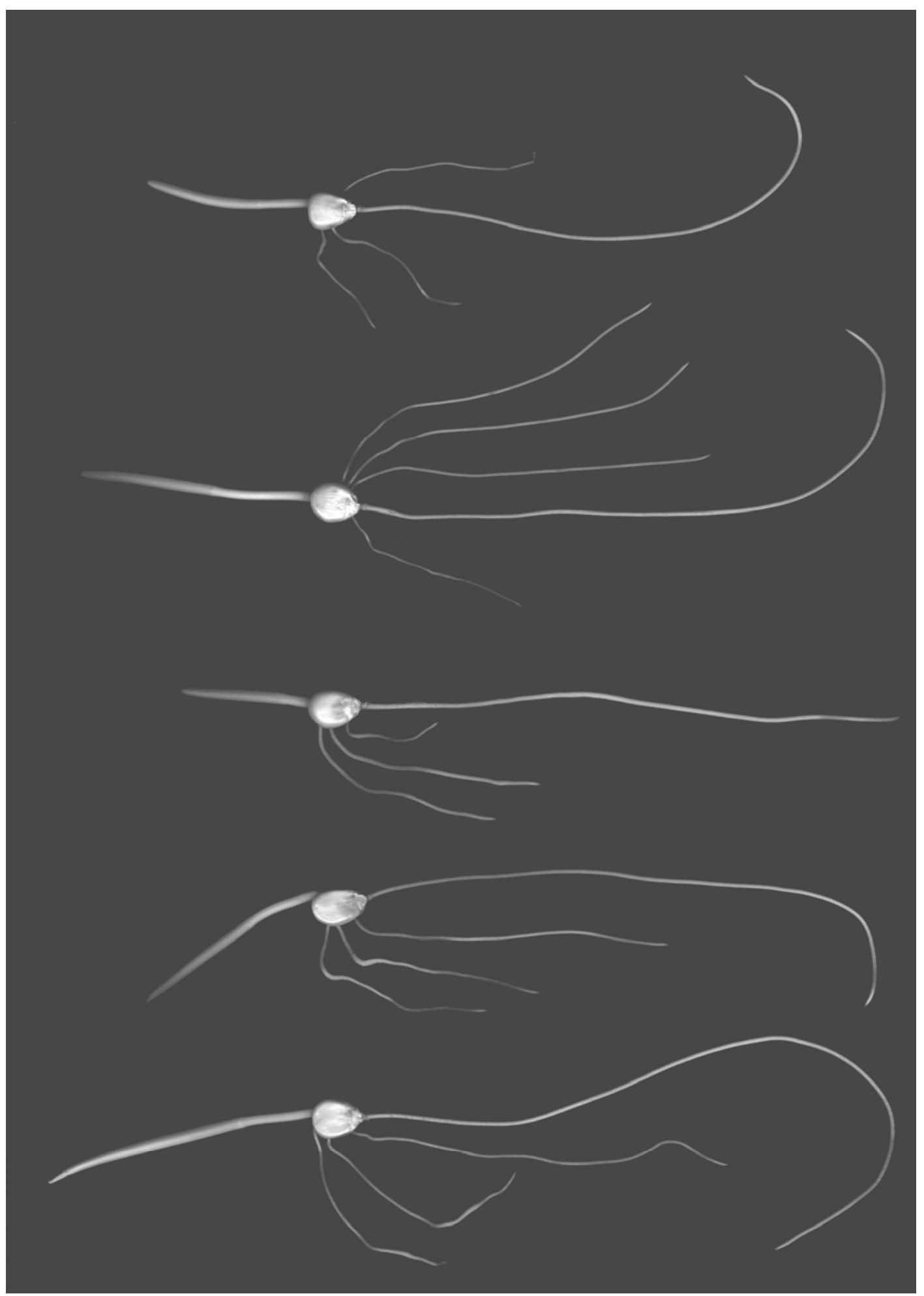

Figura 7 - Imagem digital amostrada do lote 4, pronta para a análise com o uso da rotina de processamento 


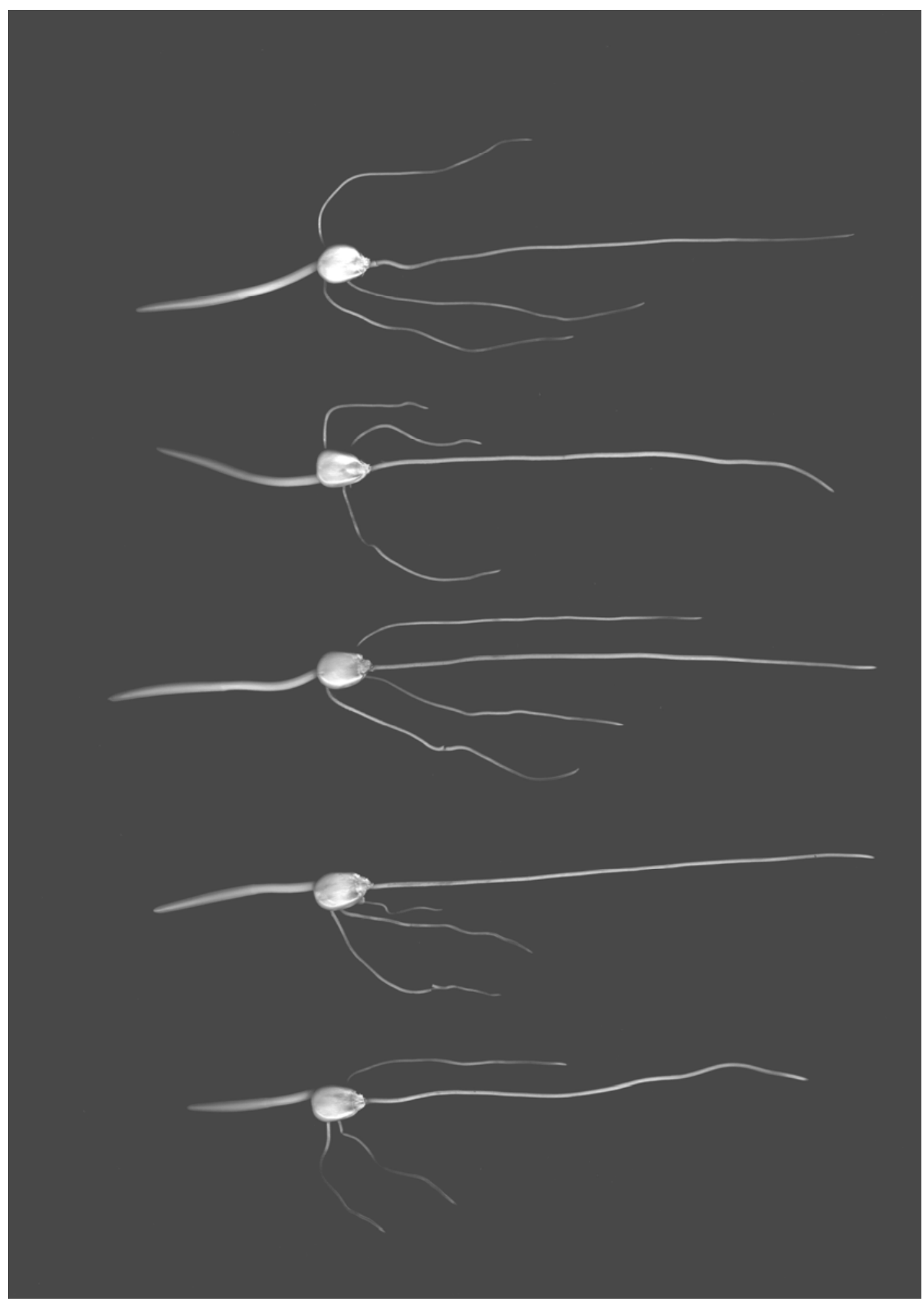

Figura 8 - Imagem digital amostrada do lote 5, pronta para a análise com o uso da rotina de processamento 
Tabela 2. Rotina computacional nomeada EFT_SkiLLMeasure versão 3.3 referente à mensuração do comprimento de plântulas intactas de milho, analisadas através do processamento da imagem, na plataforma gráfica Scil-Image

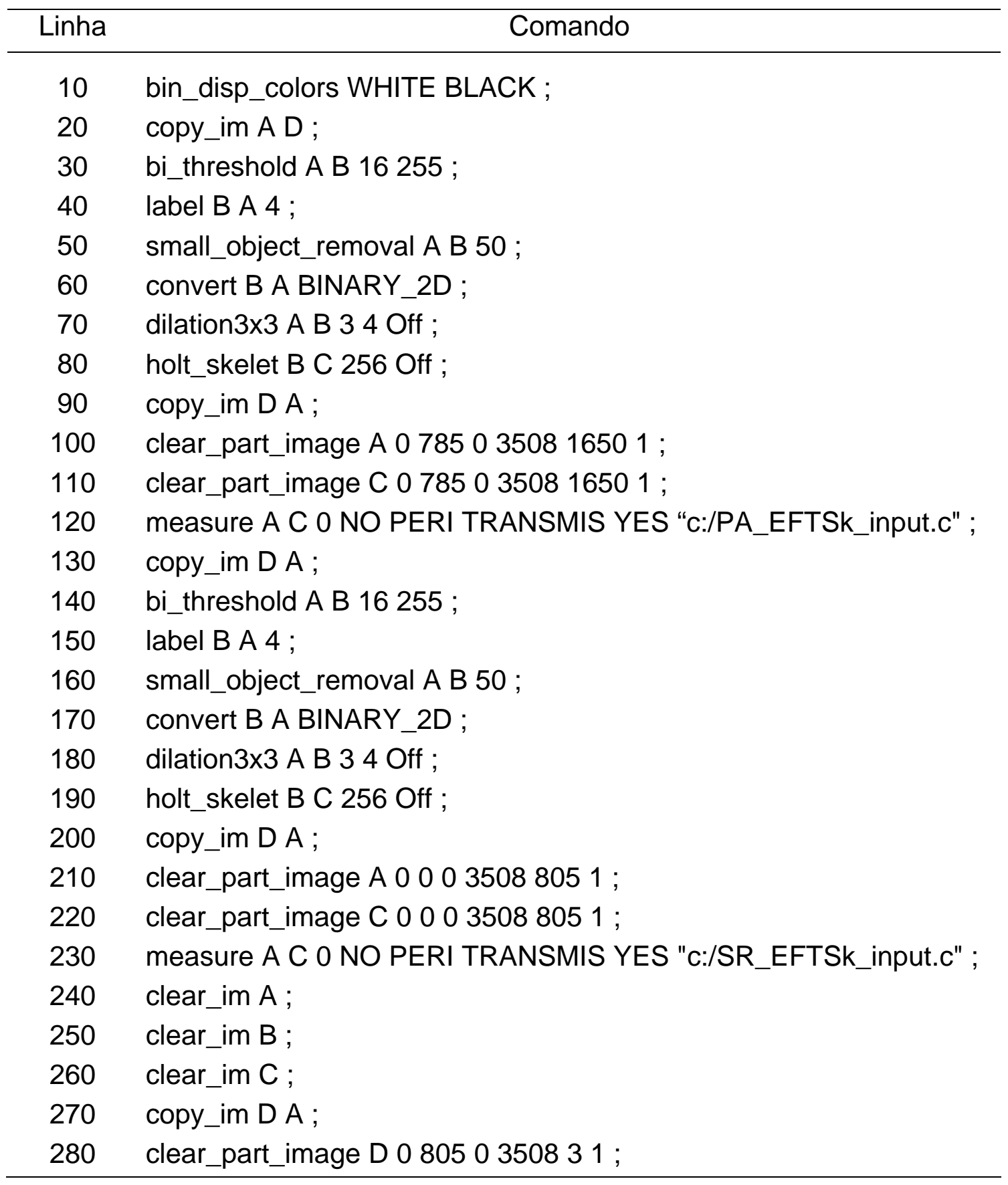


Entre as décadas de 60 e 70, Benoit Mandelbrot começou a estudar e a categorizar a geometria de uma ampla variedade de fenômenos naturais irregulares e compreendeu que todas essas formas geométricas tinham algumas características comuns bastante notáveis (Teixeira, 2000).

Então foi criada a geometria fractal, que forja padrões por um simples processo iterativo, ou seja, a repetição incessante de uma certa operação geométrica (Pimenta, 1999).

Sendo assim, a nova matemática da complexidade é essencialmente uma matemática de padrões visuais (Capra, 1996).

A ação de medição é um processo iterativo aonde os "pixels" formadores dos esqueletos vão sendo rastreados um a um e, partindo-se da dimensão já conhecida de seus lados $(L)$ são obtidas as diagonais $\left(L V^{-} 2\right)$ que, conectadas, determinarão a extensão do segmento (Figura 10).

Houve medição da extensão total (Barros \& Dias, 1992; Nakagawa, 1999), com a soma usual do comprimento do coleóptilo ao comprimento da maior raiz de cada plântula (Figura 12), sendo que, também se utilizou a rotina para o processamento e análise não usual, do comprimento do coleóptilo somado ao de todo sistema radicular (Figura 13).

Para o processamento da extensão total, com a soma usual do comprimento do coleóptilo ao comprimento da maior raiz de cada plântula, procederam-se às ações de exclusão (Figura 11) das menores raízes das plântulas das imagens originais, utilizando-se a função borracha, com cor de fundo, no programa de desenho gráfico "Photoshop", obtendo-se outras duzentas imagens alteradas, com plântulas apenas com a sua maior raiz. 


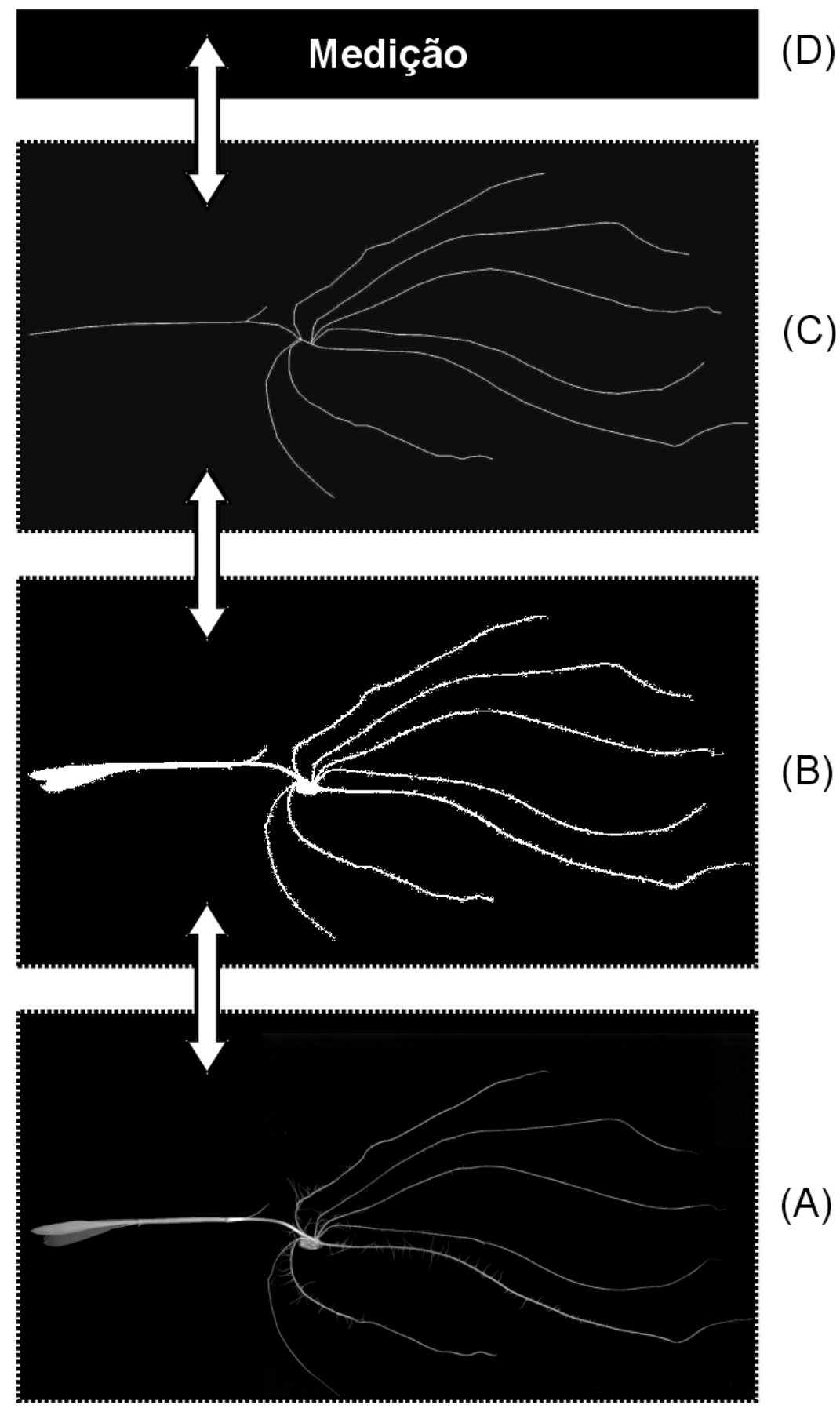

Figura 9 - Principais passos do processamento digital como representações estáticas, seguindo: 256 tons em escala de cinza (A), imagem binária $(B)$, esqueleto em imagem binária com pequenos objetos removidos (C), medição com o algoritmo "contador de pixels" (D) 


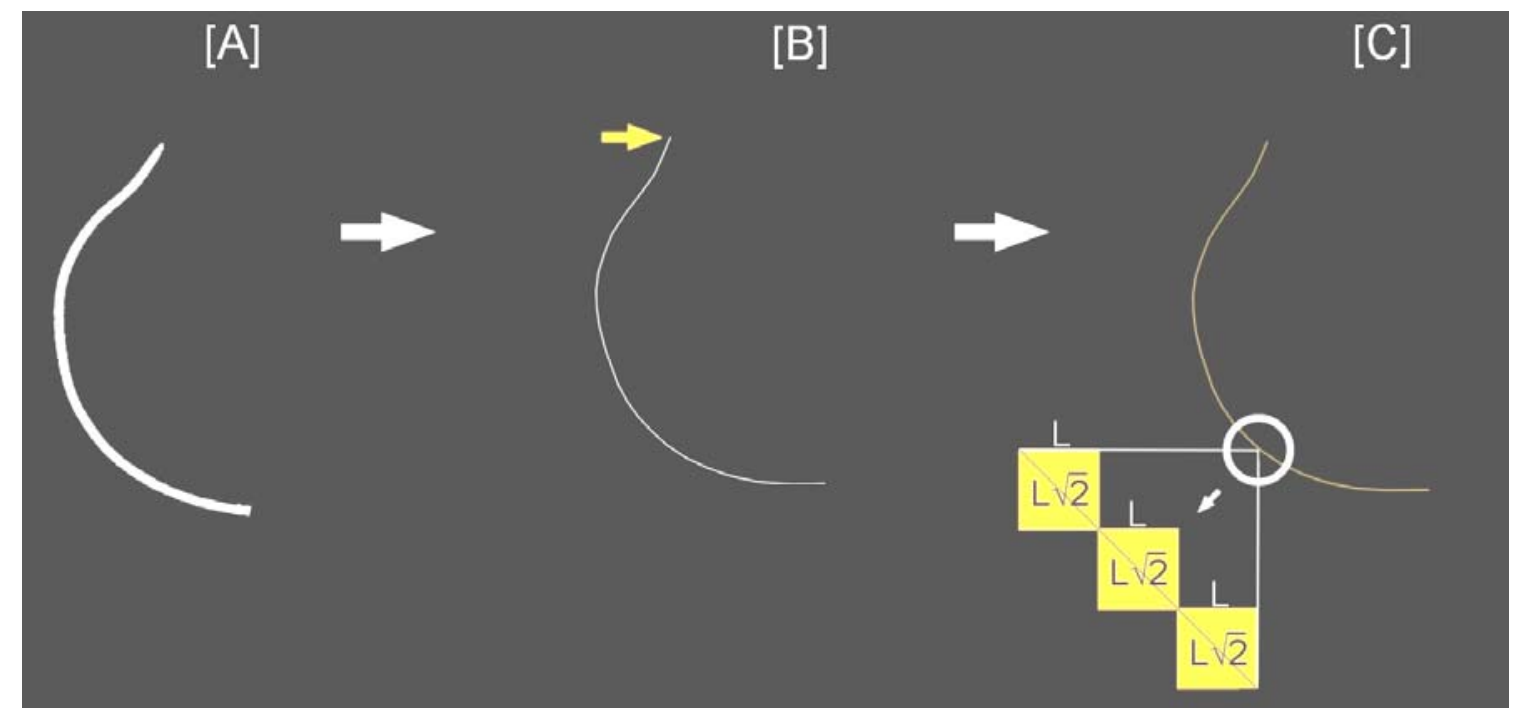

Figura 10 - Seqüência esquemática de processamento: imagem binária $(A)$, esqueleto em imagem binária $(B)$, detecção e medição pelo algoritmo contador de pixels, via análise de unidades discretas (C)

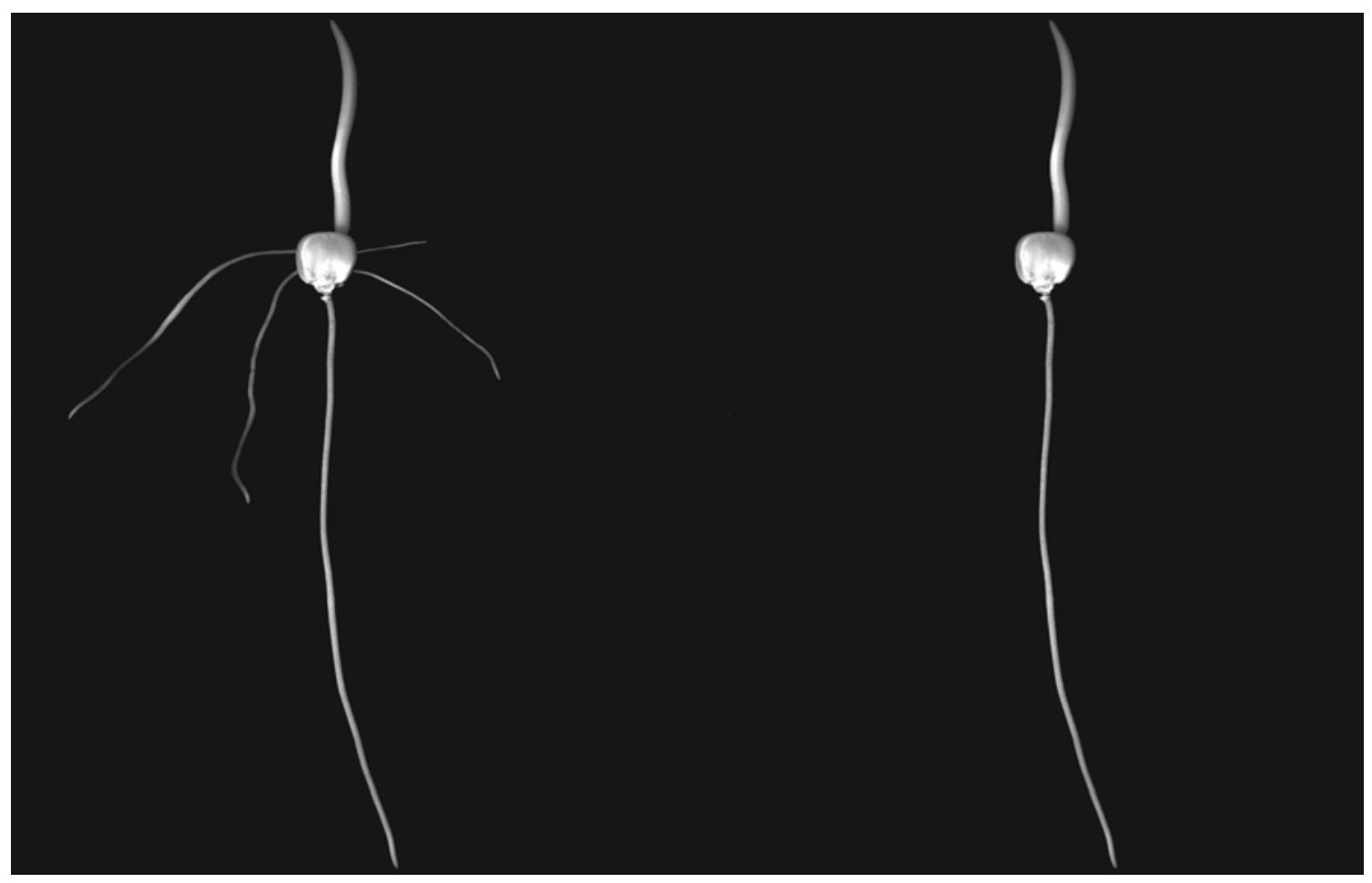

Figura 11 - Pré-processamento em imagem digital (esquerda) para alteração, com a retirada das menores raízes da plântula (direita) 


\subsubsection{Coleóptilo e raiz principal}

Os resultados obtidos com a análise estatística da medição digital das plântulas de milho oriundas dos cinco lotes de sementes do cultivar AG122 indicaram que, a partir da soma usual do coleóptilo com a maior raiz em cada plântula normal (Figura 12), totalizada em termos de média aritmética para cada lote avaliado (Figura 14), foi possibilitada a categorização dos lotes em dois níveis de vigor (Tabela 3).

As sementes do lote 1 foram inclusas em um nível considerado como de maior potencial fisiológico. As sementes dos lotes 2 e 5 foram inclusas no nível considerado como o de menor potencial fisiológico.

A não existência de diferença estatisticamente significativa nos lotes $3 \mathrm{e}$ 4 comparados aos lotes 1, 2 e 5, impossibilitou uma separação com categorização mais ampla.

Os resultados demonstraram uma semelhança de grandezas entre os lotes 3 e 4 não evidenciada como categoria, podendo ser inclusos no rol de lotes com sementes de maior potencial fisiológico ou no rol de lotes de sementes com menor potencial fisiológico, de acordo com criterização posterior, com a ajuda dos outros testes.

Cabe destacar que a medição do comprimento usual, com auxílio do processamento de imagens digitais apresentou na análise o menor coeficiente de variação dentre as três medições propostas (Tabela 3), sendo que a menor complexidade do esqueleto obtido com a transformação das plântulas explica a aproximação mais precisa feita pelos cálculos durante a contagem de "pixels" em relação à medição da plântula inteira. 


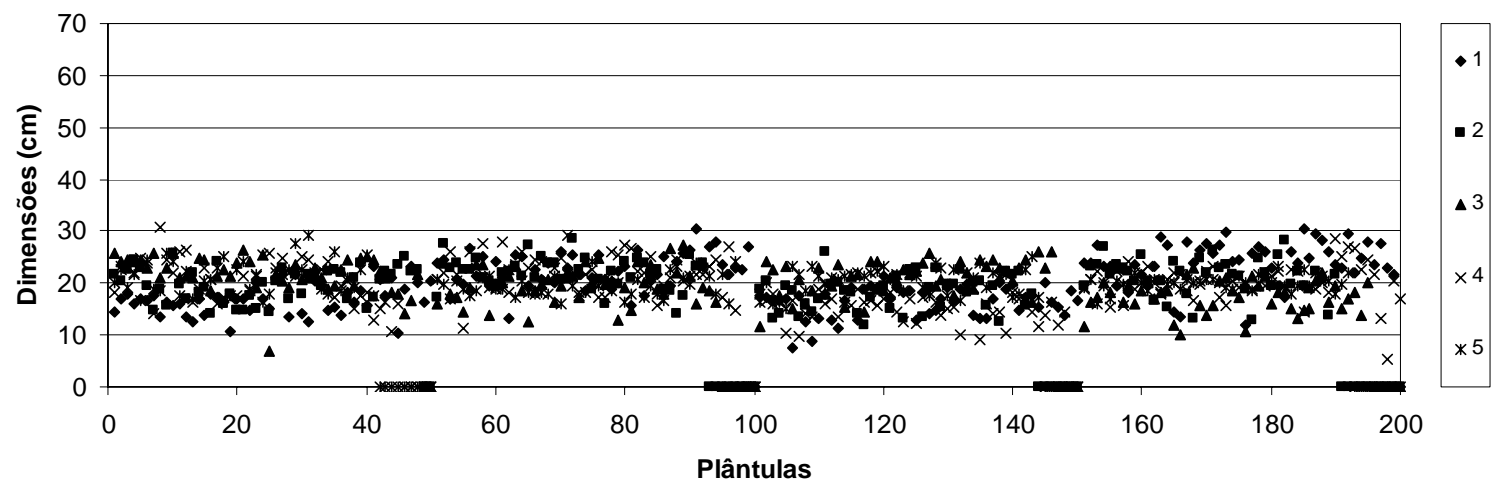

Figura 12 - Dados do procedimento computacional de medição usual do comprimento do coleóptilo mais a raiz principal (CRPp) de plântulas dos cinco lotes, em amostras de duzentas sementes inicialmente semeadas

Os dados obtidos através do processamento de imagens digitais corroboram a avaliação manual quanto à medição do comprimento de partes da plântula de milho (Tabela 3) para se determinar o vigor relativo de lotes de sementes, quando postas para germinar sob condições controladas de ambiente em laboratório, geralmente idênticas às empregadas no teste padrão de germinação.

Segundo Perry (1981), pequenas diferenças nas condições controladas de ambiente em laboratório podem ocasionar mudanças consideráveis nas avaliações feitas, como foi observado para temperatura no crescimento da radícula e da parte aérea em milho (Blacklow, 1972).

As diferenças nas análises observadas entre vários laboratórios comparados, originaram-se principalmente nas variações da temperatura recomendada e no tempo de duração do teste, sendo que, em alguns casos o tempo variou em mais ou menos oito horas (Barros \& Dias, 1992).

Buscando-se melhorar a sensibilidade do teste de crescimento de plântulas no sentido de se estreitar as diferenças entre resultados de análises adotadas como rotineiras, sugere-se a mudança da duração do teste para horas 
e a utilização de procedimento padrão para obtenção e arquivamento de dados numéricos relativos ao desenvolvimento.

\subsubsection{Coleóptilo e sistema radicular}

Totalizando-se médias aritméticas (Figura 14) e analisando-se os resultados obtidos com a medição não usual das plântulas de milho através da soma do coleóptilo com todo sistema radicular (Figura 13) em cada plântula normal oriunda dos cinco lotes de sementes do cultivar AG122, foi possível a categorização dos lotes avaliados em dois níveis de vigor (Tabela 3 ).

Consideraram-se as sementes do lote 1 como de maior potencial fisiológico, enquanto que as sementes dos lotes 2 e 5 foram consideradas como de menor potencial fisiológico.

Os lotes 3 e 4 não obtiveram diferença entre si, sendo que, também não houve a existência de diferença entre as grandezas avaliadas nos lotes 3 e 4 comparadas aos lotes 1, 2 e 5, o que não demonstrou uma identificação plena dos lotes 3 e 4 como outra categoria, podendo ser ranqueados, tanto como lotes com sementes de maior potencial fisiológico como lotes de sementes com menor potencial fisiológico havendo, para isso, necessidade de decisão posterior com base em critério elaborado a partir das análises obtidas nos outros testes.

O procedimento com medição não usual de plântulas inteiras produziu como resultado o maior coeficiente de variação dentre as três propostas de medição (Tabela 3).

Tal fato pode ser resultante da maior complexidade dos esqueletos formados, pois, algumas conexões de raízes muito próximas são, às vezes, remontadas próximo ao eixo de conexão como um único eixo conectado, advindo daí uma menor sensibilização para os cálculos durante a contagem de "pixels", e uma aproximação menos precisa. 


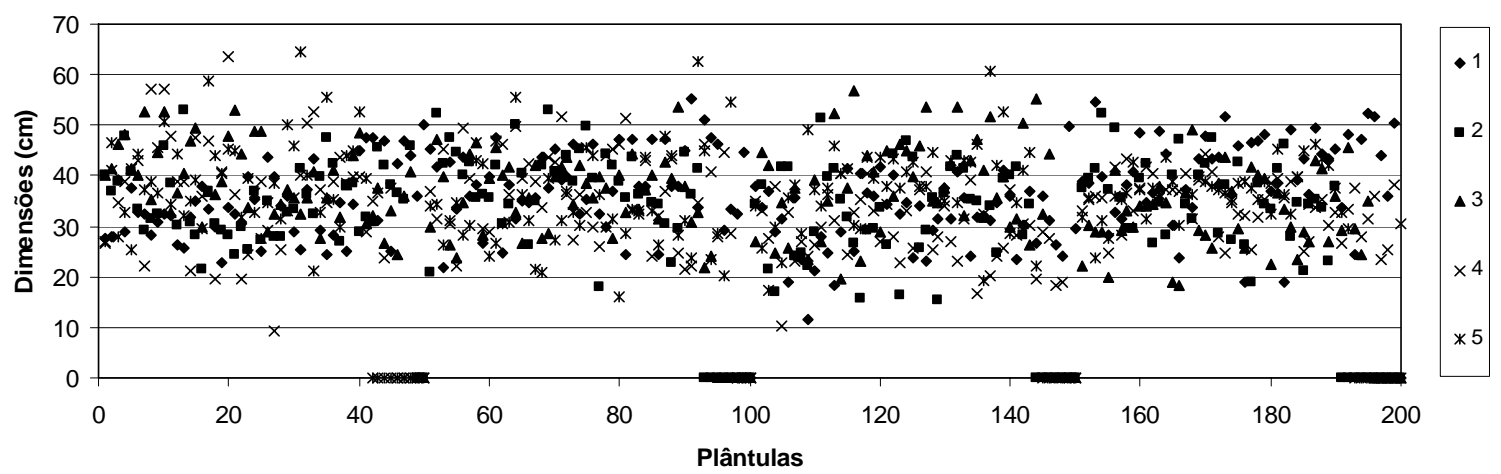

Figura 13 - Dados do procedimento computacional de medição não usual do comprimento do coleóptilo mais o sistema radicular (CSRp) de plântulas dos cinco lotes, em amostras de duzentas sementes inicialmente semeadas

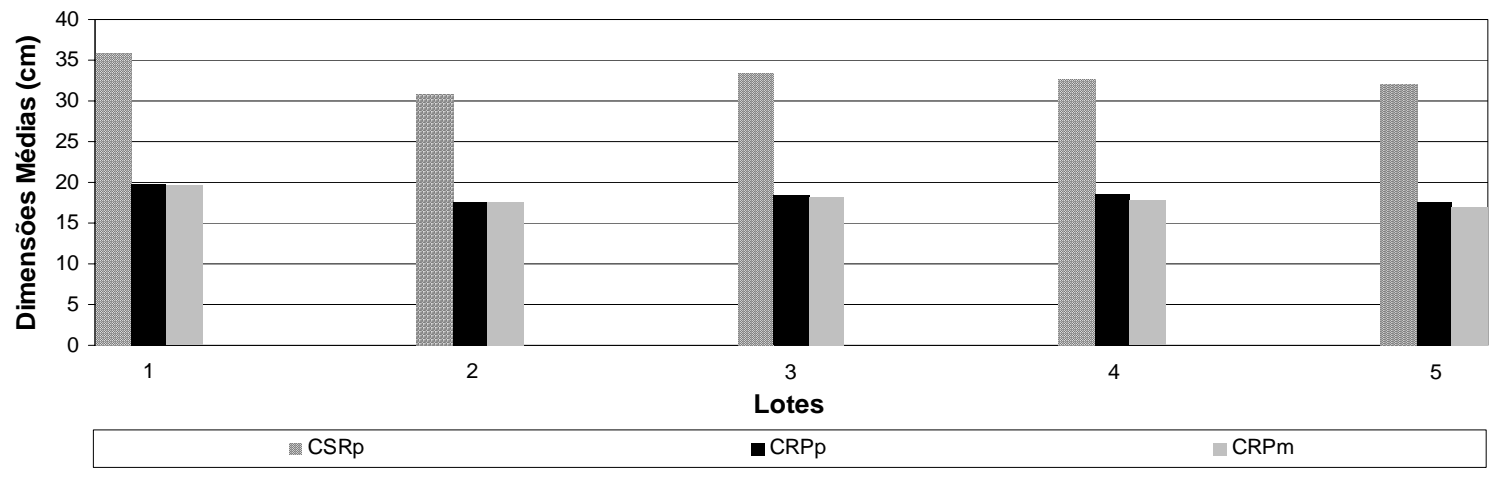

Figura 14 - Comprimento médio das plântulas dos cinco lotes, sendo as avaliações do coleóptilo mais sistema radicular via processamento (CSRp), do coleóptilo mais raiz principal via processamento (CRPp) e do coleóptilo mais raiz principal via medição manual (CRPm) 
Tabela 3. Qualidade das sementes dos cinco lotes analisados, avaliada pelo teste de crescimento de plântulas, onde se observa: CRPm (coleóptilo mais raiz principal via medição manual), CRPp (coleóptilo mais raiz principal via processamento), CSRp (coleóptilo mais sistema radicular via processamento)

\begin{tabular}{cccc}
\hline Lote & $\begin{array}{l}\text { CRPm } \\
(\mathrm{cm})\end{array}$ & $\begin{array}{l}\text { CRPp } \\
(\mathrm{cm})\end{array}$ & $\begin{array}{c}\text { CSRp } \\
(\mathrm{cm})\end{array}$ \\
\hline 1 & $19,57 \mathrm{a}^{*}$ & $19,68 \mathrm{a}$ & $35,82 \mathrm{a}$ \\
2 & $17,68 \mathrm{~b}$ & $17,58 \mathrm{~b}$ & $30,78 \mathrm{~b}$ \\
3 & $18,11 \mathrm{ba}$ & $18,34 \mathrm{ba}$ & $33,46 \mathrm{ba}$ \\
4 & $17,82 \mathrm{ba}$ & $18,57 \mathrm{ba}$ & $32,64 \mathrm{ba}$ \\
5 & $17,02 \mathrm{~b}$ & $17,66 \mathrm{~b}$ & $31,92 \mathrm{~b}$ \\
& & & 5,76 \\
\hline
\end{tabular}

*Médias, nas colunas, seguidas de mesma letra não diferem entre si pelo teste de Tukey a 5\% de probabilidade

Tabela 4. Classificação estatística do conjunto A formado pela pontuação dos testes usuais pontuação geral, formação de grupos SPM (Superior ao Médio), IM (Inferior ao Médio) e M (Médio = pontuação nula), divisão em classes de potenciais fisiológicos (PFMaior, PFMenor e PFIntermediário, onde se observa: condutividade elétrica (CE), envelhecimento acelerado (EA) e teste de frio (TF)

\begin{tabular}{ccccccc}
\hline Lote & CE & EA & TF & $\begin{array}{c}\text { Pontuação } \\
\text { Geral }\end{array}$ & $\begin{array}{c}\text { Grupo } \\
\text { M=0 }\end{array}$ & Classe \\
\hline 1 & $4+0=4^{*}$ & $1+0=1$ & $2+0=2$ & 7 & SPM & PFMaior \\
2 & $0+(-3)=-3$ & $0+(-1)=-1$ & $0+(-3)=-3$ & -7 & IFM & PFMenor \\
3 & $1+(-1)=0$ & $0+0=0$ & $0+0=0$ & 0 & M & PFInterm \\
4 & $1+(-1)=0$ & $0+0=0$ & $2+0=2$ & 2 & SPM & PFMaior \\
5 & $0+(-1)=-1$ & $0+0=0$ & $0+(-1)=-1$ & -2 & IFM & PFMenor \\
\hline
\end{tabular}

*((número de lotes estatisticamente inferiores + (-número de lotes estatisticamente superiores) = pontuação total para cada lote)) 
Tabela 5. Classificação estatística do conjunto $B$ e contagem do número de lotes pertencentes ao mesmo grupo para os conjuntos de testes $\mathrm{A}$ e $B$ com o cálculo da taxa de coincidência $\left(T C^{\star}\right)$, onde se observa: CRPm (coleóptilo mais raiz principal via medição manual), CRPp (coleóptilo mais raiz principal via processamento), CSRp (coleóptilo mais sistema radicular via processamento)

\begin{tabular}{ccccccccc}
\hline Lote & CRPm & CRPp & CSRp & $\begin{array}{c}\text { Pontuação } \\
\text { Geral }\end{array}$ & $\begin{array}{c}\text { Grupo } \\
\text { M=0 }\end{array}$ & Classe & $\begin{array}{c}\text { Conjuntos A e B } \\
\text { (presença no } \\
\text { mesmo grupo) }\end{array}$ \\
\hline & & & & & & & & \\
1 & $2+0=2^{\star \star}$ & $2+0=2$ & $2+0=2$ & 6 & SPM & PFMaior & 1 \\
2 & $0+(-1)=-1$ & $0+(-1)=-1$ & $0+(-1)=-1$ & -3 & IFM & PFMenor & 1 \\
3 & $0+0=0$ & $0+0=0$ & $0+0=0$ & 0 & M & PFInterm & 1 \\
4 & $0+0=0$ & $0+0=0$ & $0+0=0$ & 0 & M & PFInterm & 0 \\
5 & $0+(-1)=-1$ & $0+(-1)=-1$ & $0+(-1)=-1$ & -3 & IFM & PFMenor & 1 \\
& & & & & & & Total: 4 \\
\hline
\end{tabular}

*(TC $=$ número de lotes presentes no mesmo grupo . número total de lotes $\left.{ }^{-1} .100\right)$

**((número de lotes estatisticamente inferiores + (-número de lotes estatisticamente superiores) $=$ pontuação total para cada lote))

\subsection{Considerações finais}

Através da avaliação da qualidade fisiológica das sementes pelo método de análise de imagens digitais no teste de crescimento de plântulas, constataram-se diferenças de potencial fisiológico entre as sementes do lote 1 , consideradas de maior potencial fisiológico e as sementes dos lotes 2 e 5 , consideradas de menor potencial fisiológico, posto que os demais lotes (3 e 4) foram caracterizados como detentores de potencial fisiológico intermediário. Relacionado-se o método de análise de imagens digitais proposto ao método 
manual de medição, no teste de crescimento de plântulas, obteve-se a mesma resposta.

Comparada aos métodos tradicionais (Tabela 1 ) foi notada a similaridade da sensibilidade da análise via processamento (Tabela 3), respondendo pela caracterização e separação de lotes com potenciais fisiológicos distintos.

Quando as respostas obtidas nos conjuntos de testes A (Tabela 4) e B (Tabela 5) foram comparadas após a sua classificação estatística por critério de pontuação em relação ao desempenho médio (pontuação geral nula), pôde-se hierarquizar o lote 1 como de maior potencial fisiológico, os lotes 2 e 5 como de menor potencial fisiológico e o lote 3 como de potencial fisiológico intermediário.

A classificação estatística por pontuação nos conjuntos A e B teve sua inter-relação demonstrada pela taxa de coincidência de 80\% (Tabela 5) segundo o desempenho geral dos lotes em todos os testes realizados. Por esse critério, verifica-se que o lote 4 não está presente em mesmo grupo (Tabela 5), quando relacionados os conjuntos $\mathrm{A}$ e $\mathrm{B}$, oscilando entre o maior potencial fisiológico e o potencial fisiológico intermediário.

Atendo-se ao método proposto, é de suma importância o uso do conceito de banco de imagens, para organizar os arquivos produzidos e os procedimentos aplicados, sugerindo-se que primeiramente seja criado o banco, via captação, e na seqüência sejam colhidos os resultados, via processamento.

Após o acesso a imagem, os dados de comprimento de cada imagem são obtidos com tempo aproximado de processamento de três segundos.

A velocidade de processamento após o estabelecimento de um banco de quatrocentas imagens digitais, com duzentas provenientes de plântulas íntegras (Figuras 4, 5, 6, 7 e 8) e mais duzentas de plântulas só com suas maiores raízes (Figura 11), que ao rigor do experimento portavam cerca de cinco plântulas cada, totalizando aproximadamente dois mil indivíduos, mostrou que o método de análise digital apresenta alta performance.

Em termos práticos, o processamento de um banco de imagens supera pela rapidez uma avaliação manual, além de assegurar que um mesmo lote 
possa ser novamente processado, com um mesmo padrão de avaliação, em caso de dúvidas na sua análise.

A formação de falhas de integridade nas representações em processamento, produzidas por sombras nas imagens (Figura 15), próximas das conexões entre as raízes e a parte aérea, poderá ser notada com antecipação, observado-se o banco de imagens com análise visual na tela do computador.

O procedimento de medição não usual (CSRp), por envolver raízes menores e mais delgadas, predispõe ao aparecimento de sombreamentos. A rotina computacional foi desenvolvida com passos para a solução dessas falhas durante o processamento, sendo pouco provável que tais sombreamentos prejudiquem a medição.

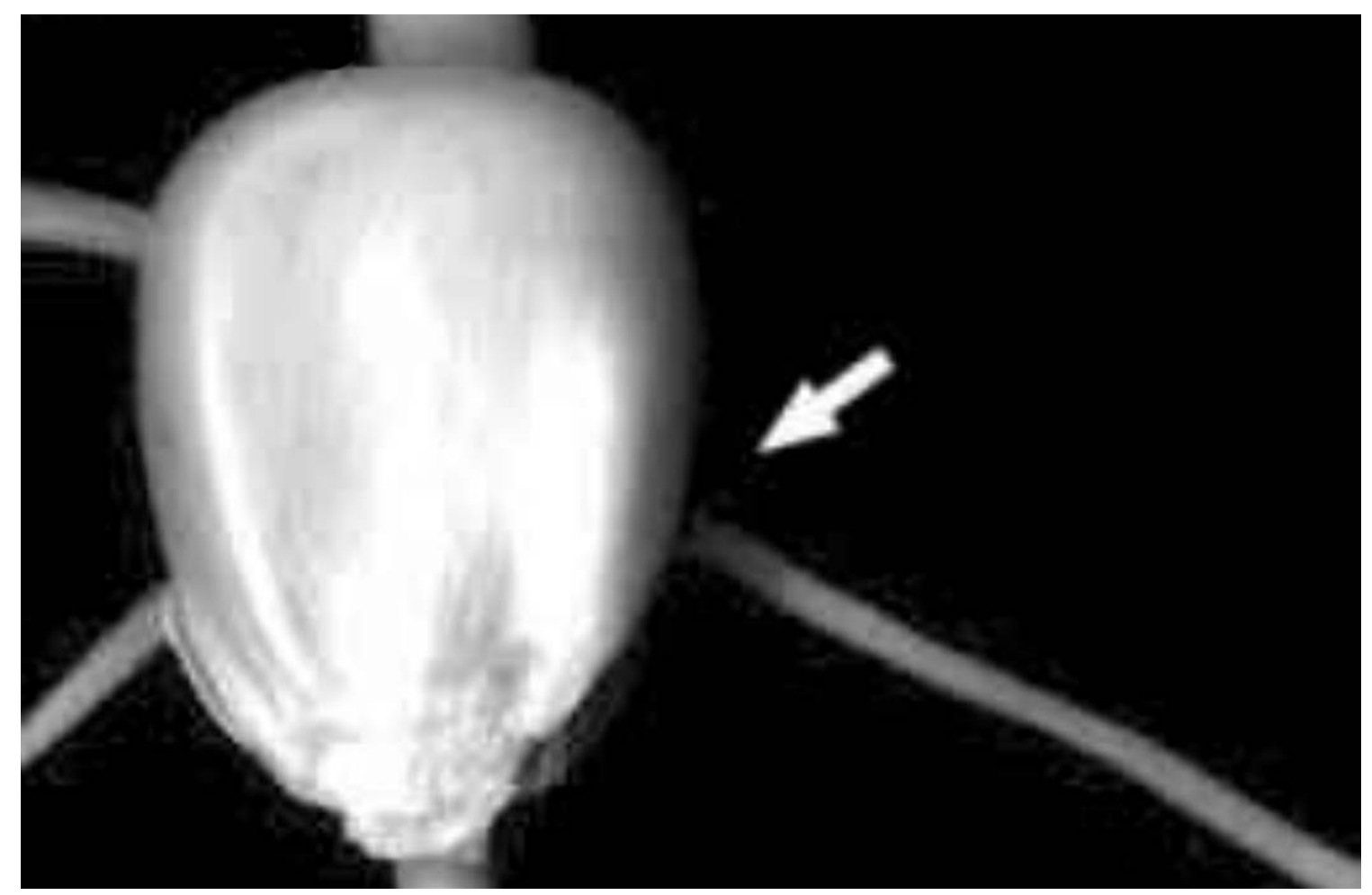

Figura 15 - Formação de sombras numa imagem digital podendo causar falhas de integridade no objeto em processamento 
Em regra prática, a distância produzida pelo sombreamento entre um eixo radicular e a plântula, com dimensão visual de até duas vezes a largura do coleóptilo, será solucionada com nova conexão sem comprometimento à análise. Caso contrário, observar-se-á pequena medida listada no relatório, em decorrência do reconhecimento do eixo radicular como objeto distinto.

No processamento com a medição usual da plântula envolvendo apenas a maior raiz (CRPp), não ocorrem falhas de integridade devido às estruturas estarem mais próximas da superfície do "scanner" durante a digitalização.

Assim, o procedimento manual de retirada das menores raízes de cada plântula logo antes de sua disposição na superfície do "scanner" é solução rápida e prática para a análise digital, sendo adicionalmente um maximizador do número de plântulas a figurarem dentro de uma mesma imagem, diminuindo muito o número de imagens requeridas para uma avaliação.

A folha de poliéster (transparência) sobre a qual são dispostas as plântulas na superfície de leitura do "scanner" deve ser trocada por uma nova folha a cada imagem captada, pois as plântulas aderem favoravelmente ao material. Folhas usadas podem ser limpas com lenços de papel e reutilizadas.

Usa-se para a troca o gabarito feito para a inserção, com a folha feita de plástico PVA ou papel cartolina na dimensão A4, a ser recolocado após a leitura ótica, entre a superfície de vidro do "scanner" e a face de poliéster.

É indispensável colocar as plântulas sobre a folha de poliéster, estando esta sobre a folha de inserção, antes que se insira o conjunto formado pela folha de poliéster e as plântulas no "scanner".

As folhas de inserção possibilitam a criação de muitos conjuntos antes de sua digitalização, organizando as tarefas, além de facilitarem o levantamento e manipulação dos conjuntos, que são muito maleáveis, dando-lhes sustentação e evitando o contato indesejado entre mãos e o vidro da superfície de leitura que deverá ser limpa, em manutenção, com o uso preferível de lenços de papel.

Através da comparação dos comprimentos processados pela computação gráfica com os comprimentos obtidos manualmente, verifica-se 
que o método digital viabiliza análises dimensionais apuradas em alta performance, com possibilidades de ajustes no procedimento para análises de plântulas de outras espécies.

Alguns ajustes na rotina de processamento EFT_SkiLLMeasure em sua versão 3.3, possibilitaram a medição do comprimento de plântulas de sorgo, em ensaios realizados durante a execução deste trabalho, sendo que, foram necessárias duas imagens, com as mesmas especificações das imagens obtidas com as plântulas de milho para se arquivar uma amostra de quarenta plântulas de sorgo, bem como, tempos semelhantes para o seu processamento.

Cabe notar que métodos de processamento e análise de imagens digitais para a determinação de parâmetros dimensionais se mostram hábeis no controle da expressão do tamanho, abrindo a possibilidade de utilização no campo de avaliações para o melhoramento de plantas. 


\section{CONCLUSÃO}

A análise de imagens digitais possibilita a associação dos dados obtidos no processamento das imagens a eventuais diferenças de vigor existentes em lotes de sementes de milho, de maneira similar a outros métodos destinados à avaliação do vigor de sementes da referida espécie. 


\section{REFERÊNCIAS BIBLIOGRÁFICAS}

ASSOCIATION OF OFFICIAL SEED ANALYSTS. Seed vigor testing handbook. Lincoln, 1983. 93p.

BARROS, A.S.R.; DIAS, M.C.L.L. Aferição de testes de vigor para sementes de milho. Informativo ABRATES, v.2, n.4, p.10-22, 1992.

BARROS, A.S.R.; DIAS, M.C.L.L.; CICERO, S.M.; KRZYZANOWSKI, F.C. Teste de frio. In: KRZYZANOWSKI, F. C.; VIEIRA, R. D.; FRANÇA NETO, J.B. (Ed.). Vigor de sementes: conceitos e testes. Londrina: ABRATES, 1999. cap.5, p.1-15.

BLACKLOW, W.M. Influence of temperature on germination and elongation of the radicle and shoot of corn (Zea mays L.). Crop Science, v.12, n.5, p.647650, 1972.

BRASIL. Ministério da Agricultura, do Abastecimento e da Reforma Agrária. Regras para análise de sementes. Brasília, 1992. 365p.

CALIARI, M.F.; MARCOS FILHO, J. Comparação entre métodos para a avaliação da qualidade fisiológica de sementes de ervilha (Pisum sativum (L.)). Revista Brasileira de Sementes, v.12, n.3, p.52-75, 1990. 
CAPRA, F. A teia da vida. Uma nova compreensão científica dos sistemas vivos: a matemática da complexidade/geometria fractal. São Paulo: Ed. Cultrix, 1996. 84p.

CARVALHO, N.M. Vigor de sementes. In: CICERO, S.M.; MARCOS FILHO, J.; SILVA, W.R. (Org.). Atualização em produção de sementes. Campinas: Fundação Cargill, 1986. p.207-223.

CARVALHO, N.M.; NAKAGAWA, J. Sementes: ciência, tecnologia e produção. 4. ed. Jaboticabal: Funep, 2000. 588p.

CICERO, S.M. Programa de controle de qualidade de sementes de milho da empresa Sementes Colorado. Piracicaba: ESALQ, Departamento de Agricultura, 1994. 44p. (Relatório Técnico).

CICERO, S.M.; HEIJDEN, G.W.A.M.; BURG, W.J.; BINO, R.J. Evaluation of mechanical damages in seeds of maize (Zea mays L.) by X-ray and digital imaging. Seed Science and Technology, v.26, n.3, p.603-612, 1998.

CRUVINEL, P.E.; CRESTANA, S.; JORGE, L.A.C. Métodos e aplicações do processamento de imagens digitais. In: CRESTANA, S.; CRUVINEL, P.E.; MASCARENHAS, S.; BISCEGLI, C.I.; MARTIN-NETO, L.; COLNAGO, L.A. (Ed.). Instrumentação agropecuária: contribuições no limiar do novo século. Brasília: EMBRAPA, SPI, 1996. p.91-151.

CUSTÓDIO, C.C.; MARCOS FILHO, J. Potassium leachate test for the evaluation of soybean seed physiological quality. Seed Science \& Technology, v.25, p.549-564, 1997. 
DAN, E.L.; MELLO, V.D.C.; WETZEL, C.T.; POPNIGS, F.; SOUZA, E.P. Transferência de matéria seca como método de avaliação do vigor de sementes de soja. Revista Brasileira de Sementes, v.9, n.3, p.45-55, 1987.

DAY, J.B. Color scanning handbook. Upper Saddle River: Prentice Hall PTR, 1997. 267p.

DELOUCHE, J.C. Observaciones sobre deterioración de semillas. Semillas, v.1, n.1, p. 8-11, 1976.

EDJE, O.T.; BURRIS, J.S. Physiological and biochemical changes in deteriorating soybean seeds. Proceedings of the Association of Official Seed Analysts, v.60, p.158-166, 1970.

FACON, J. Oportunidades do processamento de imagens na pesquisa agropecuária. In: SIMPÓSIO NACIONAL DE INSTRUMENTAÇÃO AGROPECUÁRIA - SIAGRO, São Carlos, 1996. Anais. Brasília: EMBRAPA, SPI, 1996. p.31-38.

FERGUSON, J.M. AOSA perspective of seed vigor testing. Journal of Seed Technology, v.17, n.2, p. 101-104, 1993.

GONZALEZ, R.C.; WINTS, P.A. Digital image processing. Reading: AddisonWesley Publishing, 1987. 431p.

GONZALEZ, R.C.; WOODS, R.E. Digital image processing. New York: Addison-Wesley Publishing, 1992. 705p. 
GUNASEKARAN, S.; COOPER, T.M.; BERLAGE, A.G. Evaluating quality factors of corn and soybeans using a computer vision system. Transactions of the ASAE, v.31, n.4, p.1264-1271, 1988.

HOWARTH, M.S.; STANWOOD, P.C. Tetrazolium staining viability seed test using color image processing. Transactions of the ASAE, v.36, n.6, p.19371940, 1993.

IHRIG, S.; IHRIG, E. Scanning: the professional way. Berkeley: Osborne McGraw-Hill, 1997. 148p.

INTERNATIONAL SEED TESTING ASSOCIATION. Handbook of vigor test methods. Zürich, 1981. 72p.

IRIGON, D.L.; ROSSINI, M.C. Aferição de testes de vigor para sementes de trigo. Informativo ABRATES, v.2, n.2, p.7-16, 1992.

JORGE, L.A.C.; CRESTANA, S. SIARCS 3.0: novo aplicativo para análise de imagens digitais aplicado a ciência do solo. In: CONGRESSO LATINO DE CIÊNCIA DO SOLO, 13., Águas de Lindóia, 1996. Solo Suelo 96. Campinas: Sociedade Brasileira de Ciência do solo, 1996. p.5.

KEYS, R.D.; MARGAPURAM, R.G.; REUSCHE, G.A. Automated seedling length measurement for germination/vigor estimation using a CASAS (Computerized Automated Seed Analysis System). Journal of Seed Technology, v.9, n.1, p.40-53, 1984.

KRANZIER, G.A. Applying digital image processing in agriculture. Agricultural Engineering, v.66, n.3, p. 11-13, 1985. 
KRZYZANOWSKI, F.C. Teste de comprimento de raiz de plântulas de soja. Informativo ABRATES, v.2, n.1, p.11-14, 1991.

KRZYZANOWSKI, F.C.; MIRANDA, Z.F.S. Relatório do comitê de vigor da ABRATES. Informativo ABRATES, v.1, n.1, p.7-25, 1990.

KRZYZANOWSKI, F.C.; FRANÇA NETO, J.B.; HENNING, A.A. Relato dos testes de vigor disponíveis para as grandes culturas. Informativo ABRATES, v.1, n.2, p.15-50, 1991.

KRZYZANOWSKI, F.C.; MIRANDA, Z.F.S.; OLIVEIRA, M.C.N. Aferição de testes de vigor para sementes de soja. Informativo ABRATES, v.3, n.4, p.19-31, 1993.

KRZYZANOWSKI, F.C.; VIEIRA, R.D.; FRANÇA NETO, J.B. Vigor de sementes: conceitos e testes. Londrina: ABRATES, 1999. 218p.

MARCOS FILHO, J. Teste de envelhecimento acelerado. In: KRZYZANOWSKI, F.C.; VIEIRA, R.D.; FRANÇA NETO, J.B. (Ed.). Vigor de sementes: conceitos e testes. Londrina: ABRATES, 1999. cap.3, p.1-24.

MARCOS FILHO, J.; CICERO, S.M.; SILVA, W.R. Avaliação da qualidade das sementes. Piracicaba: FEALQ, 1987. 230p.

MARTINS, L.; SILVA, W.R. Interpretação de dados obtidos em testes de vigor, realizados em laboratório e em campo, para a comparação qualitativa entre lotes de sementes de milho. In: SEMINÁRIO PANAMERICANO DE SEMILLAS, 19., Asunción, 2004. Conferencias y resumos de trabajos presentados. Asunción: FELAS, 2004. p.270. 
McCORMAC, A.C.; KEEF, P.D.; DRAPER, S.R. Automated vigour testing of field vegetables using image analysis. Seed Science Technology, n. 18, p.103-112, 1990.

McDONALD, M.B. The history of seed vigor testing. Journal of Seed Technology, v.17, n.2, p. 93-100, 1993.

McDONALD, M.B.; EVANS, A.; BENNETT, M.A. Using scanners to improve seed/seedling evaluations internationally. In: OHIO STATE UNIVERSITY. Reports of Department of Horticulture and Crop Science. 2000 julho, p.6-9.

McDONALD, T.; CHEN, Y.R. Application of morphological image processing in agriculture. Transactions of the ASAE, v.33, n.4, p. 1345-1352, 1990.

NAKAGAWA, J. Testes de vigor baseados na avaliação das plântulas. In: VIEIRA, R.D.; CARVALHO, N.M. (Ed.). Testes de vigor em sementes. Jaboticabal: FUNEP, 1994. p. 59-65.

NAKAGAWA, J. Testes de vigor baseados no desempenho das plântulas. In: KRZYZANOWSKI, F.C.; VIEIRA, R.D.; FRANÇA NETO, J.B. (Ed.). Vigor de sementes: conceitos e testes. Londrina: ABRATES, 1999. cap.2, p.1-24.

PERRY, D.A. Report of the Vigour Test Committee 1977-1980. Seed Science \& Technology, v.9, n.1, p.115-128, 1981.

PIMENTA, E.D.M. Teleantropos: a desmaterialização da cultura material, arquitetura enquanto inteligência, a metamorfose planetária. Lisboa: Ed. Estampa, 1999. 380p. 
SÁ, M.E. Relações entre a qualidade fisiológica, disponibilidade hídrica e desempenho de sementes de soja (Glycine Max (L.) Merril). Piracicaba, 1987. 147p. Tese (Doutorado) - Escola Superior de Agricultura "Luiz de Queiroz", Universidade de São Paulo.

SAKO, Y.; McDONALD, M.B.; FUJIMURA, K.; EVANS, A.F.; BENNETT, M.A. A system for automated seed vigour assessment. Seed Science \& Technology, v.29, p. 625-636, 2001.

SCOTT, D.J. Seed vigour. Seed Science \& Technology, v.6, n.4, p. 905-906, 1978.

TEIXEIRA, E.F. Variabilidade e variação arquitetural do sistema radicular de soja sob influência de fósforo no solo. Piracicaba, 2000. 57 p. Dissertação (Mestrado) - Escola Superior de Agricultura "Luiz de Queiroz", Universidade de São Paulo.

TEIXEIRA, E.F.; CICERO, S.M.; DOURADO NETO, D. Noções básicas sobre imagens digitais: captura, processamento e reconhecimento voltados para a pesquisa em tecnologia de sementes. Informativo ABRATES, v. 13, n. 1, p.59-65, 2003.

VIEIRA, R.D.; CARVALHO, N.M. Testes de vigor em sementes. Jaboticabal, FUNEP, 1994. 164p.

VIEIRA, R.D.; KRZYZANOWSKI, F.C. Teste de condutividade elétrica. In: KRZYZANOWSKI, F.C.; VIEIRA, R.D.; FRANÇA NETO, J.B. (Ed.). Vigor de sementes: conceitos e testes. Londrina: ABRATES, 1999. cap.4, p.1-26. 
VIEIRA JÚNIOR, P.A. Emprego da técnica de análise de imagens na determinação do comprimento e da largura de sementes de milho. Piracicaba, 1998. 153p. Dissertação (Mestrado) - Escola Superior de Agricultura "Luiz de Queiroz", Universidade de São Paulo.

VOOREN, J.G.; HEIJDEN, G.W.A.M. Measuring the size of french beans with image analysis. Plant Varieties and Seeds, v.6, n.47, p.47-53, 1993.

ZAYAS, I.; CONVERSE, H.; STEELE, J. Discrimination of whole from broken corn kernels with image analysis. Transactions of the ASAE, v.33, n.5, p.1642-1646, 1990.

ZONTA, E.P.; MACHADO, A.A. Sistema de análise estatística para microcomputadores - SANEST. Pelotas: UFPel, 1984. (Registro SEI 06606-0, Categoria AO). 